OPEN ACCESS

Edited by:

Cesare Piazza

Istituto Nazionale dei Tumori

(IRCCS), Italy

Reviewed by:

Sanjeev Mohanty,

Sri Ramachandra University, India

A. B. Zulkiflee,

University Malaya Medical

Centre, Malaysia

*Correspondence:

Dylan Chew

dylan.chew@nhs.net

Specialty section:

This article was submitted to Otorhinolaryngology - Head and Neck

Surgery,

a section of the journal

Frontiers in Surgery

Received: 27 March 2020 Accepted: 08 June 2020

Published: 16 July 2020

Citation:

Chew D, Green V, Riley A, England RJ and Greenman J (2020) The Changing

Face of in vitro Culture Models for

Thyroid Cancer Research: A

Systematic Literature Review.

Front. Surg. 7:43.

doi: 10.3389/fsurg.2020.00043

\section{The Changing Face of in vitro Culture Models for Thyroid Cancer Research: A Systematic Literature Review}

\author{
Dylan Chew ${ }^{1 *}$, Victoria Green ${ }^{2}$, Andrew Riley ${ }^{2}$, Richard James England ${ }^{1,2}$ and \\ John Greenman ${ }^{2}$ \\ 1 Department of ENT, Hull University Teaching Hospitals NHS Trust, Castle Hill Hospital, London, United Kingdom, \\ ${ }^{2}$ Department of Biomedical Sciences, University of Hull, Hull, United Kingdom
}

Background: Thyroid cancer is the most common endocrine malignancy worldwide. Primary treatment with surgery and radioactive iodine is usually successful, however, there remains a small proportion of thyroid cancers that are resistant to these treatments, and often represent aggressive forms of the disease. Since the 1950s, in vitro thyroid culture systems have been used in thyroid cancer research. In vitro culture models have evolved from 2-dimensional thyrocyte monolayers into physiologically functional 3-dimensional organoids. Recently, research groups have utilized in vitro thyroid cancer models to identify numerous genetic and epigenetic factors that are involved with tumorigenesis as well as test the efficacy of cytotoxic drugs on thyroid cancer cells and identify cancer stem cells within thyroid tumors.

Objective of Review: The objective of this literature review is to summarize how thyroid in vitro culture models have evolved and highlight how in vitro models have been fundamental to thyroid cancer research.

Type of Review: Systematic literature review.

Search Strategy: The National Institute for Health and Care Excellence (NICE) Healthcare and Databases Advanced Search (HDAS) tool was used to search EMBASE, Medline and PubMed databases. The following terms were included in the search: "in vitro" AND "thyroid cancer". The search period was confined from January 2008 until June 2019. A manual search of the references of review articles and other key articles was also performed using Google Scholar.

Evaluation Method: All experimental studies and review articles that explicitly mentioned the use of in vitro models for thyroid cancer research in the title and/or abstract were considered. Full-text versions of all selected articles were evaluated. Experimental studies were reviewed and grouped according to topic: genetics/epigenetics, drug testing/cancer treatment, and side populations (SP)/tumor microenvironment (TME).

Results: Three thousand three hundred and seventy three articles were identified through database and manual searches. One thousand two hundred and sixteen articles remained after duplicates were removed. Five hundred and eighty nine articles were excluded based on title and/or abstract. Of the remaining 627 full-text articles: 
24 were review articles, 332 related to genetic/epigenetics, 240 related to drug testing/treatments, and 31 related to SP/TME.

\begin{abstract}
Conclusion: In vitro cell culture models have been fundamental in thyroid cancer research. There have been many advances in culture techniques- developing complex cellular architecture that more closely resemble tumors in vivo. Genetic and epigenetic factors that have been identified using in vitro culture models can be used as targets for novel drug therapies. In the future, in vitro systems will facilitate personalized medicine, offering bespoke treatments to patients.
\end{abstract}

Keywords: thyroid cancer, in vitro, thyrocyte, organoids, epigenetics, drugs, cancer stem cells

\section{INTRODUCTION}

Thyroid cancers are the most common endocrine malignancies worldwide (1). In most developed countries the incidence of thyroid cancer has been steadily rising, partially attributed to an increased diagnosis of subclinical papillary micro-carcinomas (2). Despite its prevalence, the overall mortality rate of thyroid cancer has remained low (0.5 per 100,000 patients) (3). Surgery followed by radioactive-iodine (RAI) therapy continue to be the first line treatment modalities for thyroid cancer. Overall survival rates following primary treatment are high (>98\% 5-year survival), however, for the $1-2 \%$ of patients with aggressive forms of the disease or the $5-10 \%$ of patients with distant metastases, the prognosis is far worse (4).

Thyroid cancer research is focused on improving our understanding of the biological mechanisms that initiate and propagate the disease in the hope of refining diagnoses and formulating bespoke treatments to improve patient outcomes. An essential foundation of this research is the use of in vitro experimental models. In the simplest terms, an in vitro culture model is comprised of a vessel (e.g., dish, plate, or well) containing a culture medium to support and maintain cells outside of the body for experimental purposes. Culture models have evolved from growing homogenous cell populations in a 2-dimensional (2D) monolayer into complex 3-dimensional (3D) heterogeneous multicellular structures that resemble tissues in vivo. Cells used in these models can be derived from immortalized cell lines, pluripotent stem cells or ex-vivo human tissue. Individual patients' explanted thyroid tissue can be maintained in vitro for several days using microfluidic technology, an advancement which will open the gateway for personalized cancer medicine (5). This review summarizes how in vitro culture models have evolved and how they have been applied to thyroid cancer research.

\section{METHODS}

\section{Search Strategy}

The National Institute for Health and Care Excellence (NICE) Healthcare and Databases Advanced Search (HDAS) tool was used to search EMBASE, Medline and PubMed databases. The following terms were included in the search: "in vitro" and "thyroid cancer". The search period was confined from January
2008 until June 2019. A manual search of the references of review articles and other key articles was also performed using Google Scholar.

\section{Article Selection}

All experimental studies and review articles that explicitly mentioned the use of in vitro models for thyroid cancer research in the title and/or abstract were considered (Figure 1). Full-text versions of all selected articles were evaluated. Experimental studies were reviewed and grouped according to topic: genetics/epigenetics, drug testing/cancer treatment and side populations (SP)/tumor microenvironment (TME; Figure 2).

\section{THE EVOLUTION OF CELL CULTURE MODELS}

\section{D vs. 3D}

There are two basic systems for growing cells in culture, as a single layer of cells on an artificial substrate (adherent culture) or free-floating in the culture medium (suspension culture). Thyrocyte 2D monolayer culture systems have been used since the late 1950s (6). Their main limitation is that thyrocytes are unable to arrange themselves into their normal physiological follicular structures when cultured on adherent plates in standard culture medium (7). Instead, thyrocytes are arranged into a continuous epithelial sheet, with the apical aspect of the cell facing the culture medium above and the basal aspect facing the surface of the dish (Figure 3).

When thyrocytes are suspended in non-adherent vessels containing culture medium, they arrange themselves into a follicular structure (Figure 4A). However, the orientation of the cells is such that the apical aspect with microvilli are facing outwards in contact with the culture medium (7) (Figure 4B), thus creating an "inside-out" follicle. If these insideout follicles are then embedded into a 3D substrate emulating thyroid extracellular matrix (ECM; e.g., type 1 collagen gel) the cellular polarity inverts with the microvilli facing inwards toward the follicular lumen, creating a true physiological thyroid follicle (Figure 4C). This leads to the conclusion that thyroid folliculogenesis is dependent on the presence of ECM.

Such collagen gel cultures were developed in the 1970s to enable reconstruction of thyroid follicles in vitro (8). 


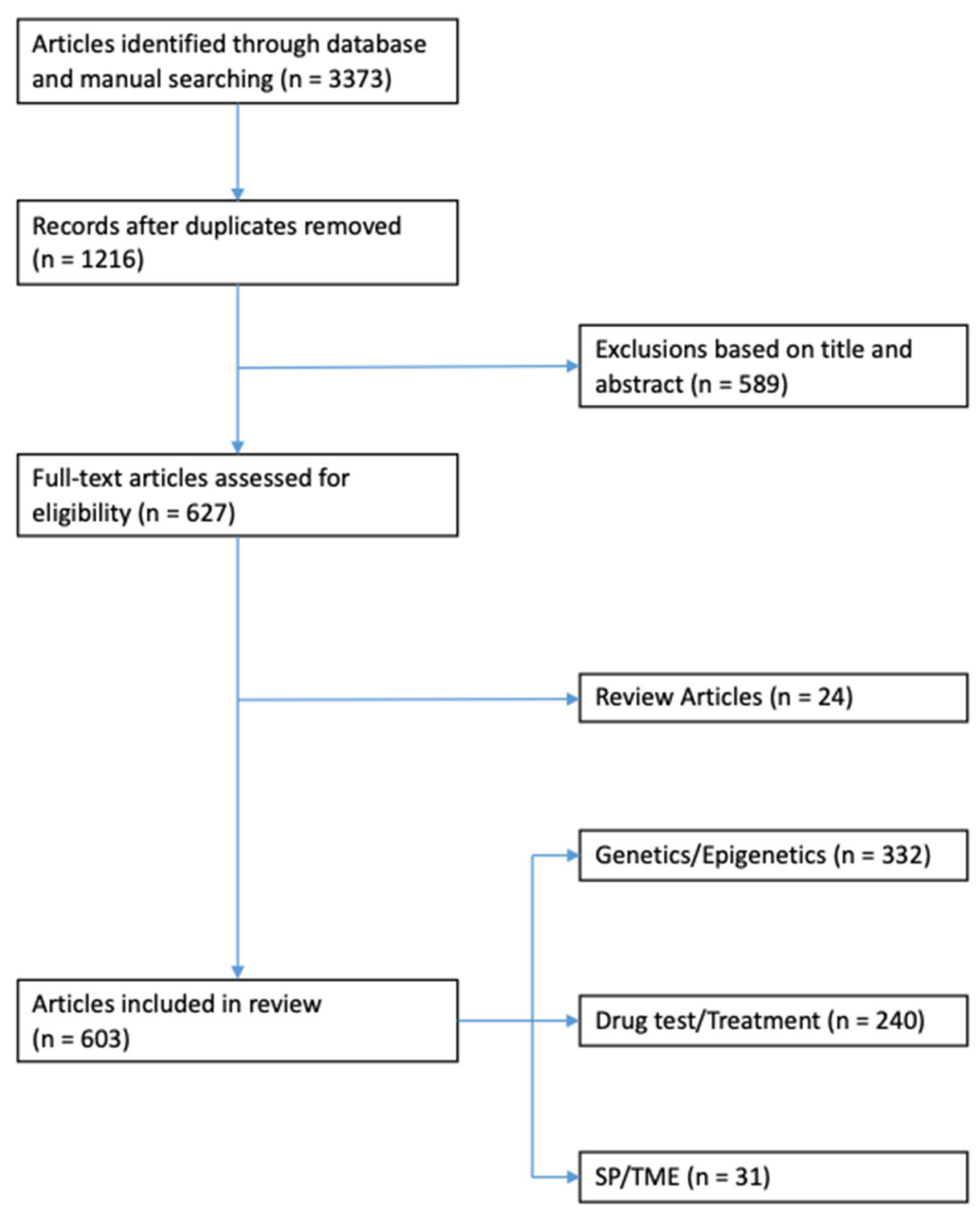

FIGURE 1 | Flowchart of article selection based on PRISMA guidelines.

These 3D culture systems have not only allowed study of thyroid folliculogenesis but also thyroid function under stimulation by factors such as thyroid stimulating hormone (TSH) and iodine, as well as interactions between thyrocytes and the ECM (9).

By replicating the in vivo thyroid cellular structure, $3 \mathrm{D}$ cell culture systems allow researchers to study the complex spatial morphology that facilitates cell-cell and cell-matrix interactions and signaling-a huge advantage over 2D monolayer culture systems (10). Advances in cell biology, microfabrication and tissue engineering have facilitated development of a wide range of 3D cell culture techniques including spheroids, organoids and microfluidic systems (11).

\section{Spheroids}

One of the most common 3D culture models used in thyroid cancer research today is the multicellular spheroid. Spheroids are cellular aggregates consisting of several thousand phenotypically distinct cells. A technique for developing spheroids was pioneered by Sutherland et al. in the early 1970s for testing the response of radiation exposure on tumor cell lines (12). The resulting dose response curves were similar to those produced when irradiating ex-vivo solid animal tumors. Since then, several techniques to create spheroids have been established including hanging drop plates, low-adhesion surface methods, and suspension culture in bioreactors which drive cells to selfaggregate under dynamic conditions (Figure 5). Spheroids can be grown to a variety of sizes, depending on the needs of the study 


\section{Thyroid Cancer Research Articles 2008-2018}

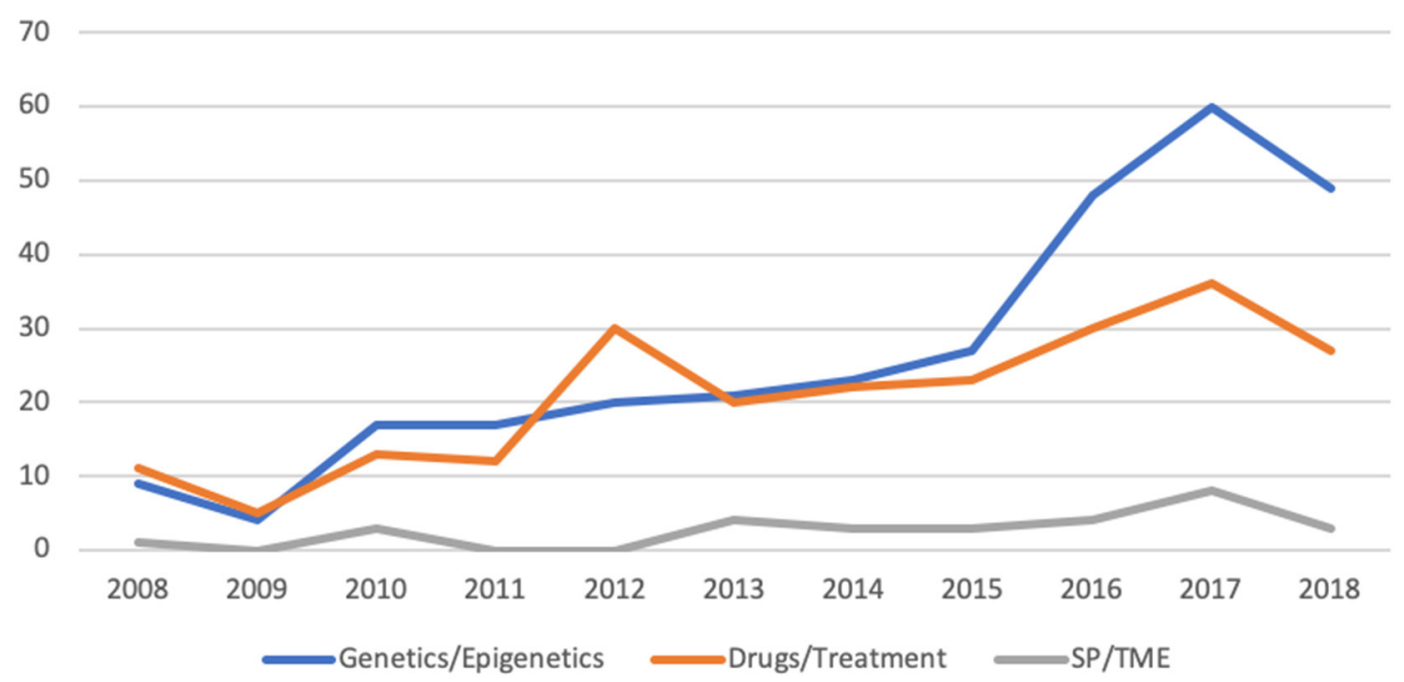

FIGURE 2 | Number of articles relating to thyroid cancer research involving in vitro culture systems published from 2008 to 2018 (as per HDAS search on 19 January 2019). SP, side populations; TME, tumor microenvironment.

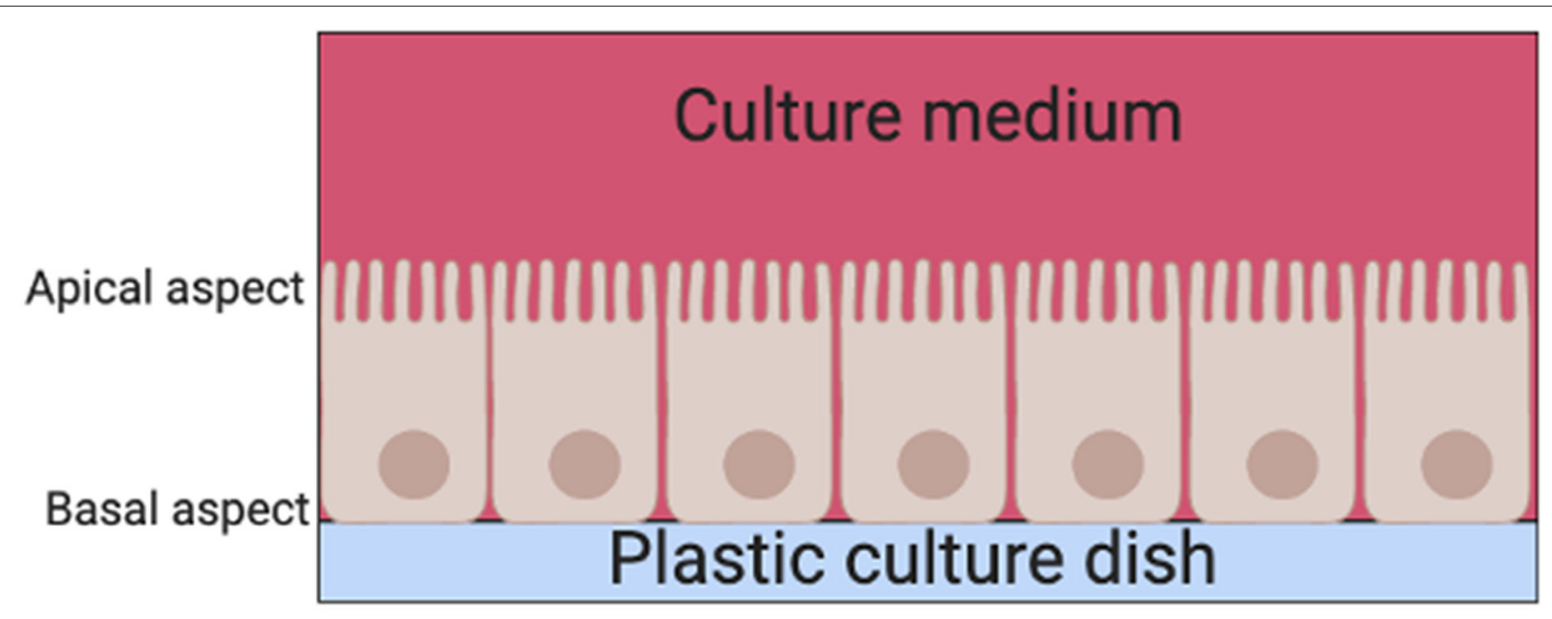

FIGURE 3 | A schema of thyrocytes in a 2D monolayer culture system.

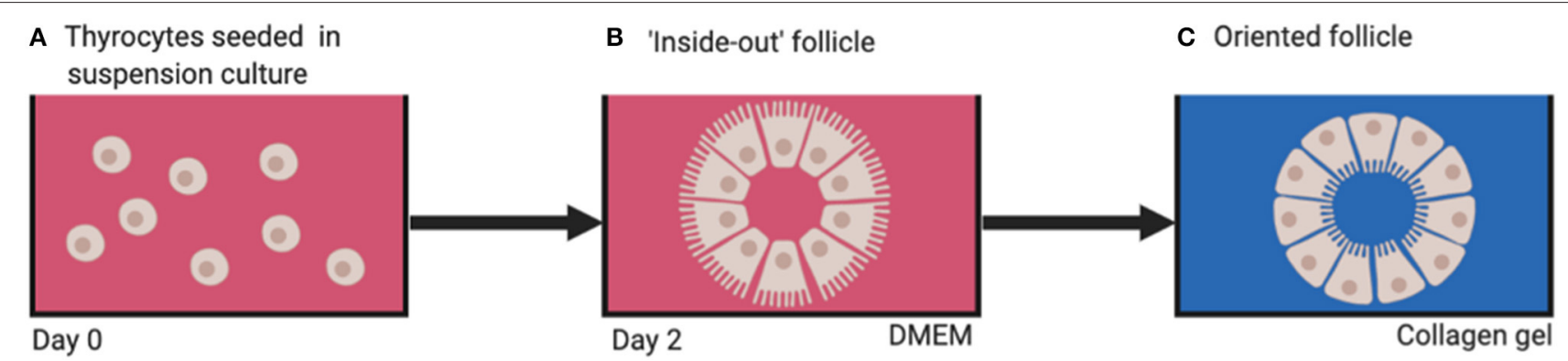

FIGURE 4 | (A) Dissociated thyrocytes placed in suspension culture, (B) "inside-out" follicles form after 2 days, (C) physiologically oriented follicles form when embedded in ECM substrate (e.g., type 1 collagen). DMEM, Dulbecco's modified eagle's medium. 


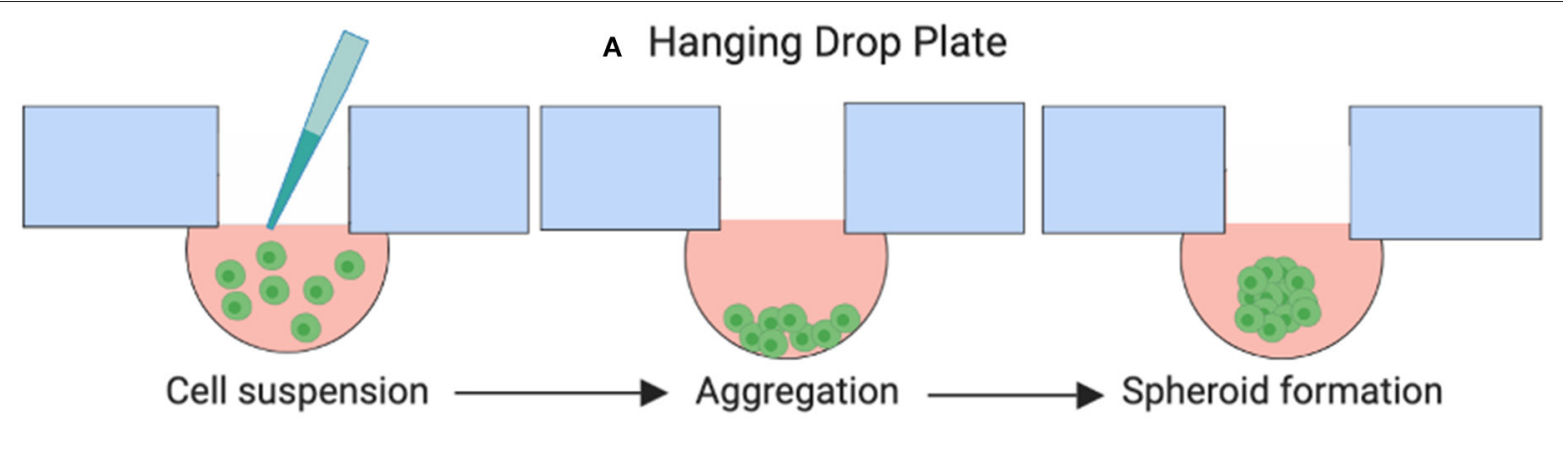

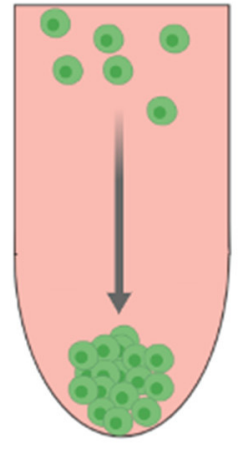

B ULA Well

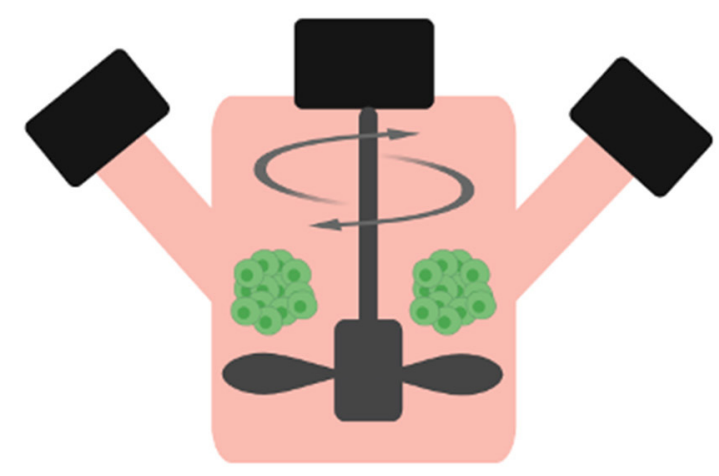

c Spinner Flask

FIGURE 5 | Three examples of spheroid formation techniques. (A) Cells suspended in droplets attached to hanging drop plates (B) Ultra-low attachment (ULA) plates prevent cells from adhering to the surface of the wells forcing them to aggregate and form spheroids, (C) cells suspended in a spinner flask are stirred by an element producing large yields of spheroids.

\section{Nutrient/Oxygen Diffusion Gradient}

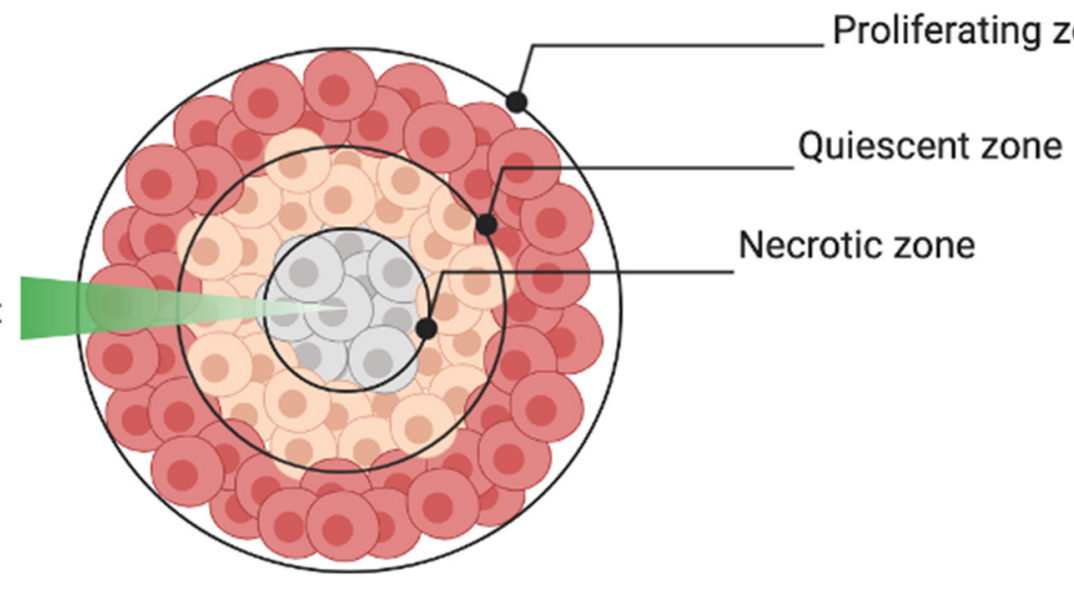

FIGURE 6 | Schematic of cellular strata within a spheroid.

(13). As well as thyrocytes, these models have been developed to include co-culture with immune cells such as macrophages (14) and neutrophils (15).

The aggregate structure of $3 \mathrm{D}$ spheroids supersedes $2 \mathrm{D}$ monolayers in terms of their ability to reproduce the cellular heterogeneity of tumors in vivo. Depending on the size of the spheroid, the structure usually consists of an outer layer of proliferating cells, a middle layer of quiescent cells and a central core of necrotic cells caused by a nutrient and oxygen diffusion gradient (Figure 6). This structural heterogeneity is important to consider when spheroids are used to test drug sensitivity.

Despite their many advantages, spheroids do present some practical challenges. Firstly, it can be difficult establishing 
spheroids from a small seed number of cells. Also, controlling proliferation, specific ratios of various co-cultured cell types and maintaining spheroids of a uniform size is not always achievable (16). This leads to issues with standardizing culture and assay protocols as well as evaluating output data (17). Currently there is no reliable, standardized highthroughput assay that allows spheroid use for drug screening. Furthermore, despite having the ability to co-culture thyroid cancer cells with select immune cells, spheroids do not entirely mimic the TME in terms of representing all the cell types present in vivo.

\section{Organoids}

Organoids are 3D in vitro cellular structures derived from either embryonic stem cells (ESC), induced pluripotent stem cells (iPSC), organ-specific adult stem cells (ACS), or primary cancer cells (18) (Figure 7). Organoids are defined by three characteristics: self-organization, multicellularity, and functionality (19). The constituent cells of an organoid are arranged into a 3D structure characteristic of the organ in vivo. They generally contain all the cell types found within that organ and execute the same functions they would normally carry out.

Novel culture systems containing laminin-rich Matrigel as a substitute for ECM and growth factors including EGF, Noggin, Wnt, and R-spondin allow the development of organoids from stem cells (20). The in vitro process utilizes the defining characteristics of stem cells: namely, the clonal expansion capacity and production of daughter cells that can differentiate into multiple cell types (21). It then relies on cell-cell and cellmatrix interaction and signaling to form the organoid structure.

Organoids have been applied to understand stem cell biology, organogenesis and pathogenesis of various diseases (10, 18, 20-26). Organoids have huge potential for modeling cancer and many organoid systems such as breast (27), colorectal (28), and prostate (29) have already been established in experimental studies. In 2018, Saito et al., established a thyroid organoid culture system from murine stem cells (25). These organoids successfully functioned as thyroid tissue, producing thyroglobulin and thyroid hormone (T3) when exposed to thyroid stimulating hormone (TSH). After p53 knockout, these organoids were xenografted into recipient mice which subsequently developed poorly differentiated thyroid cancer. Presently this is the only published study that has established a thyroid organoid as a novel experimental model.

Although organoids closely represent the cellular structure and function of in vivo tissues, there are still limitations-they often only demonstrate the initial stages of organogenesis/tumorigenesis, they lack the full range of cells that exist in the TME, and they do not develop tissue support structures such as a vascular or neuronal network (11).

\section{Microfluidic Systems}

Microfluidic systems (MFS) are devices that maintain and analyze small ex-vivo tissue samples or 3D cultured cells in a pseudo-in vivo state (30). The basic design is made up of a "chip" which houses the tissue sample connected to inlet and outlet tubing for circulating fluids. MFS mimic the human body's vasculature and lymphatics through continuous perfusion of nutrients via micro-volumes of fluid while simultaneously removing waste products. A significant advantage of maintaining tissue in these devices is that the cells remain viable and maintain tissue architecture for longer periods (3-7 days) than conventional in vitro culture systems (31).

MFS have been used to interrogate numerous types of cancer such as breast (32), lung (33), head, and neck squamous cell carcinoma (31), and only very recently thyroid cancer (5). These devices offer the ability to test drugs and RAI sensitivity of individual thyroid tumors to potentially customize/personalize therapeutic regimes.

\section{RECENT APPLICATION OF IN VITRO CULTURE SYSTEMS IN THYROID CANCER RESEARCH}

\section{Genetics and Epigenetics}

In the past ten years there have been over 300 published papers utilizing in vitro models to study the molecular biology of thyroid cancer. Mutations of genes such as RET, BRAF and RAS are widely recognized as contributing to thyroid carcinogenesis (34). These mutations lead to uncontrolled cellular proliferation, dedifferentiation and metastasis through signaling pathways such as mitogen-activated protein kinase (MAPK), phosphoinositide 3 -kinase (PI3K)/Akt, and Wnt/ $\beta$-catenin (35). Epigenetic factors, including messenger RNA (mRNA), micro RNA (miRNA) and long non-coding RNA (lncRNA), control gene expression through mechanisms such as DNA methylation and histone modification. Epigenetic factors can be over-expressed or underexpressed in thyroid cancers and activate the same signaling pathways mentioned above (Table 1).

An important feature of these epigenetic studies is the ability to reverse the effects on gene expression and observe phenotypic characteristics of the cells. The general experimental methodology described in the studies begins with collection of human thyroid cancer specimens taken at the time of surgery and extraction of the messenger RNA. Real-time polymerase chain reaction (RT-PCR) is then performed on both the malignant and adjacent healthy thyroid tissue to compare the epigenetic profiles. Following this, established thyroid cancer cell lines are manipulated to replicate the particular expression profile identified in the human tissue samples. These cell lines are then cultured in vitro as monolayers and/or spheroids to examine phenotypic characteristics such as proliferation (e.g., Ki67 staining), cell viability and apoptosis (e.g., TUNEL assay), migration and invasion (e.g., wound-closure and Transwell chamber assays).

The study of cell migration in thyroid cancer research is essential as metastatic dissemination is a significant prognostic factor. For 2D monolayer culture systems, the wound-closure and the transwell migration/invasion assays are widely used. These assays can be applied to study the migratory ability of a whole cell mass but also an individual cell's morphology (122125). Thyroid cancers that are known to have an aggressive 


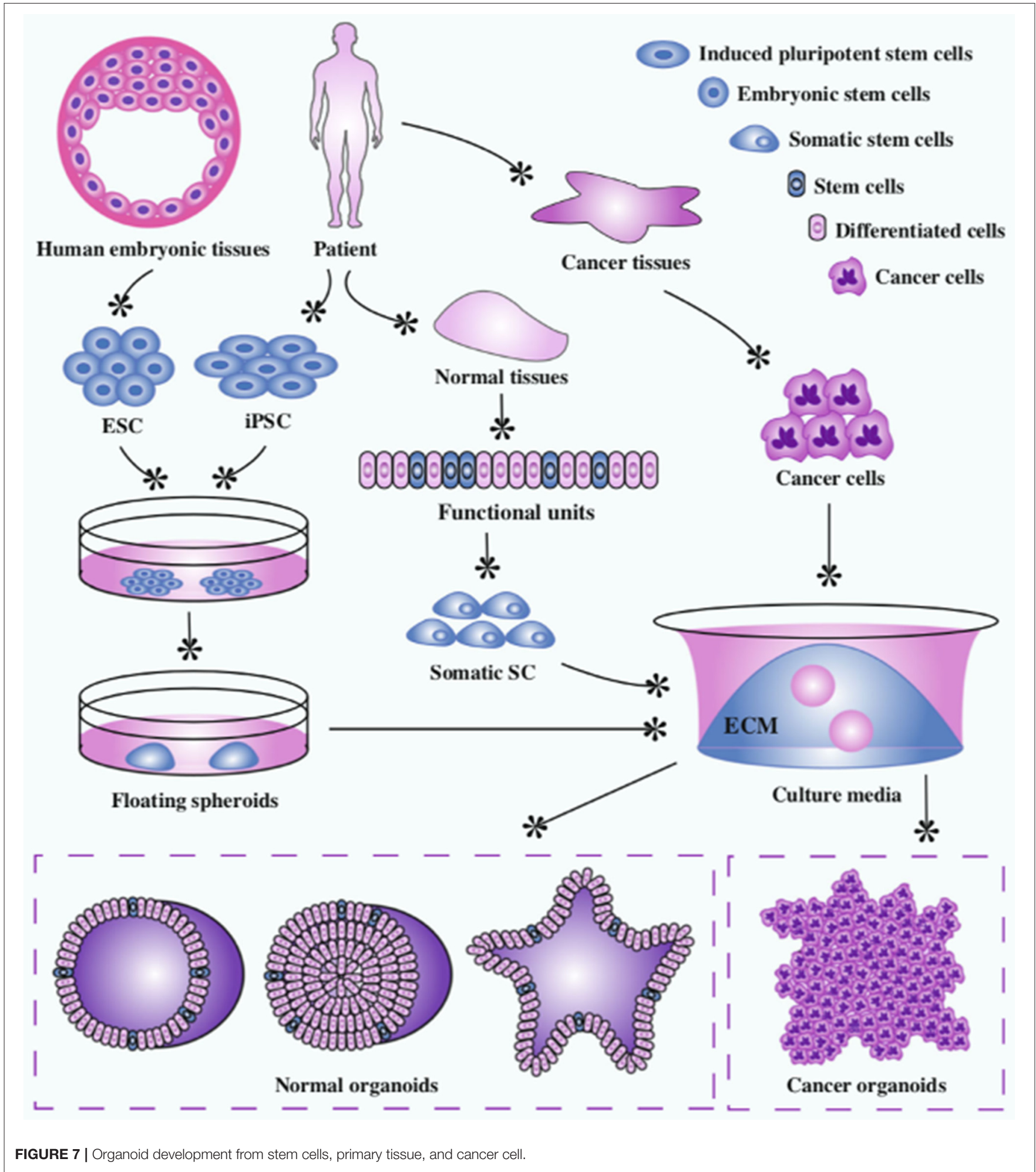

phenotype can be studied for morphological features such asb invadopodia (126).

Alternatively, thyroid cancer cells can be completely immersed into a 3D matrix-either as a single cell suspension or more commonly as a spheroid $(122,125)$. This allows cells to migrate away from the tumor mass in any direction. The extent of migration/invasion is monitored at set intervals over the course of several days. This technique offers the benefit of performing 
TABLE 1 | Studies related to genetics and epigenetics in thyroid cancer research published from Jan 2018-Jun 2019 (as per HDAS search on 19 July 2019).

Publication title

MicroRNA-125b Interacts with Foxp3 to Induce Autophagy in Thyroid Cancer

Long non-coding RNA UCA1 promotes papillary thyroid cancer cell proliferation via miR-204-mediated BRD4 activation

MiR-26a inhibits thyroid cancer cell proliferation by targeting ARPP19

Long Noncoding RNA LINC003121 Inhibits Proliferation and Invasion of Thyroid Cancer Cells by Suppression of the Phosphatidylinositol-3-Kinase (PI3K)/Akt Signaling Pathway

Long Non-coding Antisense RNA TNRC6C-AS1 Is Activated in Papillary Thyroid Cancer and Promotes Cancer Progression by Suppressing TNRC6C Expression

miR-214 regulates papillary thyroid carcinoma cell proliferation and metastasis by targeting PSMD10

DNA copy number gain-mediated IncRNA LINC01061 upregulation predicts poor prognosis and promotes papillary thyroid cancer progression

Upregulated hsa_circ_0004458 Contributes to Progression of Papillary Thyroid Carcinoma by Inhibition of miR-885-5p and Activation of RAC1

UHRF1 suppression promotes cell differentiation and reduces inflammatory reaction in anaplastic thyroid cancer

Long noncoding RNA UCA1 promotes anaplastic thyroid cancer cell proliferation via miR-135a-mediated c-myc activation miR-329 inhibits papillary thyroid cancer progression via direct targeting WNT1

miR-129 regulates growth and invasion by targeting MAL2 in papillary thyroid carcinoma

miR-218 overexpression suppresses tumorigenesis of papillary thyroid cancer via inactivation of PTEN/PI3K/AKT pathway by targeting Runx2

UCA1 promotes papillary thyroid carcinoma development by stimulating cell proliferation via Wnt pathway

SDC4 Gene Silencing Favors Human Papillary Thyroid Carcinoma Cell Apoptosis and Inhibits Epithelial Mesenchymal Transition via Wnt/ $\beta$-Catenin Pathway

c-Myc Is a Major Determinant for Antitumor Activity of Aurora A Kinase Inhibitor MLN8237 in Thyroid Cancer

CircNUP214 sponges miR-145 to promote the expression of ZEB2 in thyroid cancer cells

CLDN10 is Associated with Papillary Thyroid Cancer Progression

LncRNA XIST/miR-34a axis modulates the cell proliferation and tumor growth of thyroid cancer through MET-PI3K-AKT signaling

CITED1 promotes proliferation of papillary thyroid cancer cells via the regulation of p21 and p27

Long Noncoding RNA HOXA-AS2 Promotes Papillary Thyroid Cancer Progression by Regulating miR-520c-3p/S100A4

Pathway

KLF5 promotes the tumorigenesis and metastatic potential of thyroid cancer cells through the NF- $\mathrm{B}$ signaling pathway

TEKT4 Promotes Papillary Thyroid Cancer Cell Proliferation, Colony Formation, and Metastasis through Activating PI3K/Akt Pathway

Downregulation of MiR-431 expression associated with lymph node metastasis and promotes cell invasion in papillary thyroid carcinoma

Long noncoding RNA LINC00313 modulates papillary thyroid cancer tumorigenesis via sponging miR-4429

Long non-coding RNA BANCR regulates cancer stem cell markers in papillary thyroid cancer via the RAF/MEK/ERK

signaling pathway

LRP4 promotes proliferation, migration, and invasion in papillary thyroid cancer

MicroRNA-222 Promotes Invasion and Metastasis of Papillary Thyroid Cancer Through Targeting Protein Phosphatase 2

Regulatory Subunit B Alpha Expression

Circular RNA circZFR contributes to papillary thyroid cancer cell proliferation and invasion by sponging miR-1261 and facilitating C8orf4 expression

Long noncoding RNA PVT1 enhances the viability and invasion of papillary thyroid carcinoma cells by functioning as ceRNA of microRNA-30a through mediating expression of insulin like growth factor 1 receptor

Inhibitory roles of miR-9 on papillary thyroid cancer through targeting BRAF

Steroid receptor coactivator-1 interacts with NF-kB to increase VEGFC levels in human thyroid cancer

MicroRNA-361-5p inhibits papillary thyroid carcinoma progression by targeting ROCK1

INAVA promotes aggressiveness of papillary thyroid cancer by upregulating MMP9 expression

LncRNA SNHG12 promotes the proliferation and metastasis of papillary thyroid carcinoma cells through regulating

wnt/ $\beta$-catenin signaling pathway

LARP7 in papillary thyroid carcinoma induces NIS expression through suppression of the SHH signaling pathway

\section{References}

(36)

(37)

(38)

(39)

(40)

(41)

(42)

(43)

(44)

(45)

(46)

(47)

(48)

(49)

(50)

(51)

(52)

(53)

(54)

(55)

(56)

(57)

(58)

(60)

(61)

(62)

(63)

(64)

(65)

(66)

(67)

(68)

(69)

(70)

(71)

(72)
Models used

2D, spheroids and PDX*

2D

2D and PDX

2D and PDX

2D

$2 \mathrm{D}$

2D

2D and PDX

2D and PDX

2D, spheroids and PDX

2D and PDX

2D and PDX

2D and PDX

2D and PDX

2D

2D

2D

2D and PDX

2D

2D and PDX

2D and PDX

2D and PDX

2D and PDX

2D

$2 \mathrm{D}$

2D

2D, spheroids and PDX

2D

2D and PDX

$2 \mathrm{D}$

2D

2D and PDX

2D and PDX

2D and PDX

2D and PDX

2D and PDX

$2 \mathrm{D}$ 
TABLE 1 | Continued

\section{Publication title}

References

miR-622 suppresses tumor formation by directly targeting VEGFA in papillary thyroid carcinoma

Epigenetic Modifications in Thyroid Cancer Cells Restore NIS and Radio-lodine Uptake and Promote Cell Death

NEAT1_2 functions as a competing endogenous RNA to regulate ATAD2 expression by sponging microRNA-106b-5p in papillary thyroid cancer

Histone methyltransferase KMT5A gene modulates oncogenesis and lipid metabolism of papillary thyroid cancer in vitro

TBX3 promotes proliferation of papillary thyroid carcinoma cells through facilitating PRC2-mediated p57KIP2 repression

Effects of miR-144 on the sensitivity of human anaplastic thyroid carcinoma cells to cisplatin by autophagy regulation

Src-mediated regulation of the PI3K pathway in advanced papillary and anaplastic thyroid cancer

Long non-coding RNA CCAL promotes papillary thyroid cancer progression by activation of NOTCH1 pathway

Long glucocorticoid-induced leucine zipper regulates human thyroid cancer cell proliferation

A dual mechanism of activation of the Sonic Hedgehog pathway in anaplastic thyroid cancer: crosstalk with

RAS-BRAF-MEK pathway and ligand secretion by tumor stroma

Downregulation of CSN6 attenuates papillary thyroid carcinoma progression by reducing Wnt/ $\beta$-catenin signaling and sensitizes cancer cells to FH535 therapy

Long noncoding RNA NEAT1 regulate papillary thyroid cancer progression by modulating miR-129-5p/KLK7 expression

VASN promotes YAP/TAZ and EMT pathway in thyroid carcinogenesis in vitro

Knockdown of KDM1A suppresses tumor migration and invasion by epigenetically regulating the TIMP1/MMP9 pathway in papillary thyroid cancer

Knockdown of long noncoding RNA SNHG7 inhibits the proliferation and promotes apoptosis of thyroid cancer cells by downregulating BDNF

IGFBP7 inhibits cell proliferation by suppressing AKT activity and cell cycle progression in thyroid carcinoma

AXL Is a Novel Predictive Factor and Therapeutic Target for Radioactive lodine Refractory Thyroid Cancer

Methylglyoxal Acts as a Tumor-Promoting Factor in Anaplastic Thyroid Cancer

Functional analysis and clinical significance of the isocitrate dehydrogenase 2 gene in papillary thyroid carcinoma

NECTIN4 promotes papillary thyroid cancer cell proliferation, migration, and invasion and triggers EMT by activating AKT

TFAP2B overexpression contributes to tumor growth and progression of thyroid cancer through the COX-2 signaling pathway

Down-regulated HSDL2 expression suppresses cell proliferation and promotes apoptosis in papillary thyroid carcinoma

Mortalin (GRP75/HSPA9) Promotes Survival and Proliferation of Thyroid Carcinoma Cells

LncRNA FOXD2-AS1 Functions as a Competing Endogenous RNA to Regulate TERT Expression by Sponging miR-7-5p in

Thyroid Cancer

Interaction of BRAF-induced ETS factors with mutant TERT promoter in papillary thyroid cancer

Role of phospho-ezrin in differentiating thyroid carcinoma

Low metallothionein $1 \mathrm{M}(\mathrm{MT} 1 \mathrm{M})$ is associated with thyroid cancer cell lines progression

MiR-758-3p regulates papillary thyroid cancer cell proliferation and migration by targeting TAB1

RET Kinase-Regulated MicroRNA-153-3p Improves Therapeutic Efficacy in Medullary Thyroid Carcinoma

Identification and characterization of two novel oncogenic mTOR mutations

The Highly Expressed FAM83F Protein in Papillary Thyroid Cancer Exerts a Pro-Oncogenic Role in Thyroid Follicular Cells

High expression of NUCB2 promotes papillary thyroid cancer cells proliferation and invasion

miR-215 suppresses papillary thyroid cancer proliferation, migration, and invasion through the AKT/GSK-3ß/Snail signaling by targeting ARFGEF1

circRAPGEF5 Contributes to Papillary Thyroid Proliferation and Metastatis by Regulation miR-198/FGFR1

Loss of MADD expression inhibits cellular growth and metastasis in anaplastic thyroid cancer

Dual Oncogenic/Anti-Oncogenic Role of PATZ1 in FRTL5 Rat Thyroid Cells Transformed by the Ha-Ras ${ }^{V 12}$ Oncogene

STAT3-induced upregulation of IncRNA ABHD11-AS1 promotes tumor progression in papillary thyroid carcinoma by regulating miR-1301-3p/STAT3 axis and PI3K/AKT signaling pathway

SNHG15 functions as a tumor suppressor in thyroid cancer

A Toxicogenomic Approach Reveals a Novel Gene Regulatory Network Active in in vitro and in vivo Models of Thyroid Carcinogenesis

Downregulation of NEAT1 reverses the radioactive iodine resistance of papillary thyroid carcinoma cell via miR-101-3p/FN1/PI3K-AKT signaling pathway
(73)

(74)

(75)

(76)

(77)

(78)

(79)

(80)

(81)

(82)

(83)

(84)

(85)

(86)

(87)

(88)

(89)

(90)

(91)

(92)

(93)

(94)

(95)

(96)

(97)

(98)

(99)

(100)

(101)

(102)

(103)

(104)

(105)

(106)

(107)

(108)

(109)

(110)

(111)

(112)
Models used

2D and PDX

2D

2D

2D

2D and PDX

2D and PDX

2D

2D and PDX

2D and PDX

2D and spheroids 2D and PDX

2D and PDX

2D

2D and PDX

2D

2D and PDX

2D

2D

2D

2D

2D and PDX

2D and PDX

2D

2D, spheroids and PDX

2D and

spheroids

2D

2D

2D

2D and PDX

2D and PDX

2D and PDX

2D and PDX

2D and PDX

2D and PDX

2D and PDX

2D, spheroids and PDX

2D and PDX

2D

2D and PDX

2D and PDX 
TABLE 1 | Continued

\begin{tabular}{|c|c|c|}
\hline Publication title & References & Models used \\
\hline $\begin{array}{l}\text { Silencing of IncRNA LINC00514 inhibits the malignant behaviors of papillary thyroid cancer through miR-204-3p/CDC23 } \\
\text { axis }\end{array}$ & $(113)$ & 2D and PDX \\
\hline MicroRNA-1270 modulates papillary thyroid cancer cell development by regulating SCAI & $(114)$ & 2D and PDX \\
\hline $\begin{array}{l}\text { TBX1 Functions as a Tumor Suppressor in Thyroid Cancer Through Inhibiting the Activities of the PI3K/AKT and MAPK/ERK } \\
\text { Pathways }\end{array}$ & $(115)$ & 2D and PDX \\
\hline MicroRNA-146b-5p as an oncomiR promotes papillary thyroid carcinoma development by targeting CCDC6 & $(116)$ & 2D and PDX \\
\hline KAT5 promotes invasion and metastasis through C-MYC stabilization in ATC & $(117)$ & 2D and PDX \\
\hline $\begin{array}{l}\text { MicroRNA-766 inhibits papillary thyroid cancer progression by directly targeting insulin receptor substrate } 2 \text { and regulating } \\
\text { the PI3K/Akt pathway }\end{array}$ & (118) & 2D and PDX \\
\hline HOXD-AS1 is a predictor of clinical progression and functions as an oncogenic IncRNAs in papillary thyroid cancer & $(119)$ & $2 \mathrm{D}$ \\
\hline MiR-141-3p Suppresses Tumor Growth and Metastasis in Papillary Thyroid Cancer via Targeting Yin Yang 1 & $(120)$ & 2D and PDX \\
\hline $\begin{array}{l}\text { Long non-coding RNA LINC00152 promotes cell growth and invasion of papillary thyroid carcinoma by regulating the } \\
\text { miR-497/BDNF axis }\end{array}$ & $(121)$ & 2D and PDX \\
\hline
\end{tabular}

${ }^{*} P D X$, patient derived xenografts, in vivo models implanting human cancer cells into immunodeficient mice.

the assay without having to re-plate the cells, as well as more closely simulating cell migration from a tumor mass in vivo. The oxygen and nutrient diffusion gradient present within a spheroid structure can promote migration and invasion through changes in gene expression-not present in $2 \mathrm{D}$ culture models. The effect of co-cultured cells such as macrophages on migration and invasion of thyroid cancer cells has also been explored as these immune cells have roles in epithelial-mesenchymal transition and subsequent tumor progression $(14,15)$. These assays are also applied in research studies testing the cytotoxic effects of chemotherapy agents.

Although no single genetic/epigenetic change has been reported, in all cases of thyroid cancer there are common signaling pathways which are affected. The epigenetic factors examined in the studies listed in Table $\mathbf{1}$ were shown to have either tumor suppressive or oncogenic effects via these pathways. Suppression of the PI3K/Akt pathway through silencing of TEKT4 (59), IncRNA XIST (55), miRNA-222 (64), LRP4 (63), and NECTIN 4 (92) led to reduced cellular proliferation and migration. Similarly, PI3K/Akt suppression and subsequent reduced tumorigenesis was achieved by up-regulating LncRNALINC003121 (40), miRNA-218 (49), miRNA-34a (55), and IGFBP7 (88). Up-regulation of miRNA-153-3p (101) and silencing of lncRNA-BANCR (62), TERT (97), and FAM83F (103) led to suppression of the MAPK/ERK pathway resulting in reduced cell proliferation and increased apoptosis. Silencing oncogenes SDC4 (51), IncRNA-UCA1 (46), IncRNA-SNHG12 (71), CSN6 (83) led to decreased proliferation and invasion, and increased apoptosis through inhibition of Wnt/b-catenin pathway, whereas up-regulating miRNA-329 (47) demonstrated the same effect.

The conclusion is that epigenetic molecules have the potential to be used as biomarkers as well as targets for drug therapy. The observation that thyroid cancer progression is associated with an accumulation of epigenetic changes has led to the development of drug treatments targeting these pathways such as multitargeted tyrosine kinase inhibitors (TKIs), demethylating agents and histone deacetylase inhibitors (HDACi).

\section{Drug Testing}

Drug attrition rates for cancer are much higher than in other therapeutic areas. Only 5\% of agents that have anticancer activity in preclinical development demonstrate a sufficient efficacy in phase III testing (127). Although surgery and RAI therapy are primary therapeutic modalities for all subtypes of thyroid cancer, targeted drug therapies such as the tyrosine kinase inhibitors (TKIs) vemurafenib, sunitinib and lenvatinib are available for those patients with either rapidly progressing, recurrent or RAI-resistant thyroid cancers (128). Recent studies using in vitro models have focused on testing drug combinations to enhance tumor sensitivity to established chemotherapy agents, as well as testing novel anticancer agents and drug delivery systems (Table 2).

Nanontechnology, and more specifically manufacture of nanoparticles for drug formulation and delivery has been a promising area of research. Drug products that contain proteins or nucleic acids are susceptible to pharmacokinetic degradation. Nanoparticles can be customized for targeted delivery of drugs to improve bioavailability and provide controlled release of medication (167). For thyroid cancers, nanoparticles have been used to deliver sorafenib (149), anti-hTERT siRNA (150), capsacin for use in photothermal therapy (156), and $\mathrm{I}^{131}$ labeled anti-VEGFR2 antibodies for targeted drug delivery and have shown promising results in both in vitro and in vivo cancer models.

As with the epigenetic studies, most drug studies utilize a combination of primary human thyroid cancer cells and established cell lines. Cells are cultured in monolayers and spheroids and exposed to incremental drug levels to observe cell survival and apoptosis. Thyroid cancer cells are also injected into animal models (patient derived xenografts-PDX) and treated with drugs to validate in vitro findings.

3D culture models are emerging as improved experimental models for preclinical target identification. Although spheroids more closely resemble the tumor in vivo, there is currently no commercially available standardized high-throughput assay for drug screening. Earlier studies by Li et al. (168), Guiffrida et al. 
TABLE 2 | Studies related to targeted drug testing in thyroid cancer research published from Jan 2018 to Jun 2019 (as per HDAS search on 19 July 2019 ).

\section{Publication title}

Precision Targeted Therapy with BLU-667 for RET -Driven Cancers

The mTOR Kinase Inhibitor CZ415 Inhibits Human Papillary Thyroid Carcinoma Cell Growth

Triple action Pt(iv) derivatives of cisplatin: a new class of potent anticancer agents that overcome resistance

Targeting of the Cholecystokinin-2 Receptor with the Minigastrin Analog 177Lu-DOTA-PP-F11N: Does the Use of Protease Inhibitors Further Improve in vivo Distribution?

Recombinant oncolytic Newcastle disease virus displays antitumor activities in anaplastic thyroid cancer cells

The Synergistic Effects of Celecoxib and Sodium Valproate on Apoptosis and Invasiveness Behavior of Papillary Thyroid Cancer Cell Line in-vitro

Metformin Targets Mitochondrial Glycerophosphate Dehydrogenase to Control Rate of Oxidative Phosphorylation and Growth of Thyroid Cancer in vitro and in vivo

Selective RET kinase inhibition for patients with RET-altered cancers

Potential of the dual mTOR kinase inhibitor AZD2014 to overcome paclitaxel resistance in anaplastic thyroid carcinoma

Heme Oxygenase-1 Inhibitors Induce Cell Cycle Arrest and Suppress Tumor Growth in Thyroid Cancer Cells

Combined effects of octreotide and cisplatin on the proliferation of side population cells from anaplastic thyroid cancer cell lines

The LAT1 inhibitor JPH203 reduces growth of thyroid carcinoma in a fully immunocompetent mouse model

Synergistic effects of BET and MEK inhibitors promote regression of anaplastic thyroid tumors

Apatinib-induced protective autophagy and apoptosis through the AKT-mTOR pathway in anaplastic thyroid cancer

SoLAT (Sorafenib Lenvatinib alternating treatment): a new treatment protocol with alternating Sorafenib and Lenvatinib for refractory thyroid Cancer

S100A4 Knockout Sensitizes Anaplastic Thyroid Carcinoma Cells Harboring BRAF V600E/Mt to Vemurafenib

Lestaurtinib is a potent inhibitor of anaplastic thyroid cancer cell line models

Computational modeling reveals MAP3K8 as mediator of resistance to vemurafenib in thyroid cancer stem cells

Emodin suppresses angiogenesis and metastasis in anaplastic thyroid cancer by affecting TRAF6-mediated pathways in vivo and in vitro

PI3K blockage synergizes with PLK1 inhibition preventing endoreduplication and enhancing apoptosis in anaplastic thyroid cancer Transferrin receptor-targeted HMSN for sorafenib delivery in refractory differentiated thyroid cancer therapy

Anti-hTERT siRNA-Loaded Nanoparticles Block the Growth of Anaplastic Thyroid Cancer Xenograft

Melatonin suppresses thyroid cancer growth and overcomes radioresistance via inhibition of p65 phosphorylation and induction of ROS

Vandetanib has antineoplastic activity in anaplastic thyroid cancer, in vitro and in vivo

Lenvatinib exhibits antineoplastic activity in anaplastic thyroid cancer in vitro and in vivo

Dual effects for lovastatin in anaplastic thyroid cancer: the pivotal effect of transketolase (TKT) on lovastatin and tumor proliferation

In vitro Antitumor Activity of Aloperine on Human Thyroid Cancer Cells through Caspase-Dependent Apoptosis

Epigenetic Modifications in Thyroid Cancer Cells Restore NIS and Radio-lodine Uptake and Promote Cell Death

Novel design of NIR-triggered plasmonic nanodots capped mesoporous silica nanoparticles loaded with natural capsaicin to

inhibition of metastasis of human papillary thyroid carcinoma B-CPAP cells in thyroid cancer chemo-photothermal therapy

Inhibition of mitochondrial respiration by tigecycline selectively targets thyroid carcinoma and increases chemosensitivity

Targeting PLKs as a therapeutic approach to well-differentiated thyroid cancer

Transcript-level regulation of MALAT1-mediated cell cycle and apoptosis genes using dual MEK/Aurora kinase inhibitor "BI-847325"

on anaplastic thyroid carcinoma

Effect of Nifuroxazide on Proliferation, Migration, and Invasion of Thyroid Papillary Carcinoma Cells

Antitumor Effect of ${ }^{131}$ I-Labeled Anti-VEGFR2 Targeted Mesoporous Silica Nanoparticles in Anaplastic Thyroid Cancer

MAPK Inhibitors Enhance HDAC Inhibitor-Induced Redifferentiation in Papillary Thyroid Cancer Cells Harboring BRAF V600E: An in vitro Study

Evaluation of preclinical efficacy of everolimus and pasireotide in thyroid cancer cell lines and xenograft models

Propofol suppresses proliferation and migration of papillary thyroid cancer cells by down-regulation of IncRNA ANRIL

Discovery of Potent, Selective, and Orally Bioavailable Estrogen-Related Receptor- $\gamma$ Inverse Agonists To Restore the Sodium lodide Symporter Function in Anaplastic Thyroid Cancer

Antitumor effects of anlotinib in thyroid cancer

References Models used

(129)

(130)

(131)

(135)
2D and PDX

2D and PDX

2D, spheroids and PDX

2D

2D, spheroid and PDX

2D

2D and PDX

2D and PDX

2D, spheroid

and PDX

2D and PDX

2D and PDX

2D and PDX

2D and PDX

2D and PDX

2D and PDX

2D and PDX

2D and PDX

2D and

spheroids

2D and PDX

2D and PDX

2D and PDX

2D and PDX

2D and PDX

2D and PDX

2D and PDX

2D

2D

2D

2D

2D and PDX

2D and PDX

2D and

spheroid

2D

2D and PDX

2D

2D

2D and PDX 
(169), Hardin et al. (170) compared drug sensitivities on various types of thyroid cancer grown in $2 \mathrm{D}$ and $3 \mathrm{D}$ culture systems. They all observed that drug resistance was much higher in cells that formed spheroids than in monolayers. These findings have been attributed to the diffusion dynamics seen in spheroids as well as the discovery of side populations of cells within tumors that demonstrate stem cell-like properties.

\section{Cancer Stem Cells}

Cancer stem cell (CSC) theory challenges the classical model of carcinogenesis (where any cell in an organ has the potential to transform through gene mutations) following the discovery of distinct populations of pluripotent tumor stem-like cells within solid tumors (171). In thyroid cancer, small populations of cells within a tumor have displayed distinct CD surface antigens and gene expression (e.g., Oct 3 and 4, Nanog) that are known to be associated with stem cells identified in other forms of cancer (172) (Table 3).

Generally, the studies have used in vitro sphere formation assays and PDX (using immunedeficient murine models) to confirm the existence of CSC. In 2007, Mitsutake et al., were the first group to identify and characterize a very small side population of putative thyroid cancer stem cells (CSC; $0.02-0.25 \%$ of total number of cells) from thyroid cancer cell lines (187). The highest percentage of CSC was seen in anaplastic thyroid cancer cell lines (ATC). The CSC in this study demonstrated stem-like properties of self-renewal and differentiation potential as well as altered gene expression profiles compared with non-CSC cells.

Since then more researchers have used in vitro models to identify specific tumor markers in thyroid CSC previously validated in other types of cancer. High levels of Oct-4, SOX2, NANOG, and CD44 have been associated with thyroid $\operatorname{CSC}(53,168,170,177)$. Conversely, the cells isolated in these studies expressed low or completely absent levels of thyroid-specific differentiation markers such as TTF1, PAX8, and TSH-R.

When proliferation, migration, and cell survival assays have been applied to CSC in vitro they have demonstrated increased metastatic potential and reduced apoptosis $(170,172,182,188)$. Additionally, they are largely quiescent which allows them to escape chemotherapy agents that normally target rapidly dividing cells (169).

\section{CONCLUDING STATEMENT AND FUTURE PERSPECTIVE}

In this review we have established that in vitro cell culture models have been the workhorse in thyroid cancer research for decades. There have been many advances in culture techniquesdeveloping complex cellular architecture that more closely resemble tumors in vivo.

In vitro culture models have provided researchers with a reliable platform to study the molecular and cellular

TABLE 3 | Studies related to thyroid cancer stem cells published from 2008 to 2019 (as per HDAS search on 19 July 2019 ).

\begin{tabular}{|c|c|c|}
\hline Publication title & References & Models used \\
\hline In vitro identification and characterization of CD133(pos) cancer stem-like cells in anaplastic thyroid carcinoma cell lines & $(173)$ & 2D \\
\hline $\begin{array}{l}\text { Medullary Thyroid Carcinoma Cell Lines Contain a Self-Renewing CD133 Population that Is Dependent on Ret Proto-Oncogene } \\
\text { Activity }\end{array}$ & $(174)$ & 2D and spheroids \\
\hline Tumorigenic and Metastatic Activity of Human Thyroid Cancer Stem Cells & $(175)$ & 2D, spheroid and PDX \\
\hline Doxorubicin fails to eradicate cancer stem cells derived from anaplastic thyroid carcinoma cells: characterization of resistant cells & $(176)$ & 2D and spheroids \\
\hline $\begin{array}{l}\text { Insulin receptor isoforms and insulin-like growth factor receptor in human follicular cell precursors from papillary thyroid cancer } \\
\text { and normal thyroid }\end{array}$ & $(177)$ & 2D and spheroids \\
\hline Phenotypic Characterization of Metastatic Anaplastic Thyroid Cancer Stem Cells & $(168)$ & 2D, spheroid and PDX \\
\hline Detection of Thyroid Cancer Stem Cells in Papillary Thyroid Carcinoma & (53) & 2D, spheroid and PDX \\
\hline $\begin{array}{l}\text { SNAIL induces epithelial-to-mesenchymal transition and cancer stem cell-like properties in aldehyde dehydroghenase-negative } \\
\text { thyroid cancer cells }\end{array}$ & $(178)$ & 2D, spheroid and PDX \\
\hline Analysis of multiple markers for cancer stem-like cells in human thyroid carcinoma cell lines & $(179)$ & 2D and spheroids \\
\hline $\begin{array}{l}\text { Stemness in Human Thyroid Cancers and Derived Cell Lines: The Role of Asymmetrically Dividing Cancer Stem Cells Resistant } \\
\text { to Chemotherapy }\end{array}$ & $(180)$ & 2D and PDX \\
\hline Thyrospheres From Normal or Malignant Thyroid Tissue Have Different Biological, Functional, and Genetic Features & $(181)$ & Spheroids \\
\hline Molecular profiles of cancer stem-like cell populations in aggressive thyroid cancers & $(182)$ & 2D and spheroids \\
\hline Resistance of papillary thyroid cancer stem cells to chemotherapy & $(169)$ & Spheroids \\
\hline Generation of Novel Thyroid Cancer Stem-Like Cell Clones & $(170)$ & 2D, spheroid and PDX \\
\hline Intracellular redox status controls spherogenicity, an in vitro cancer stem cell marker, in thyroid cancer cell lines & $(183)$ & 2D and spheroids \\
\hline Thyroid Cancer Stem-Like Cell Exosomes: Regulation of EMT via Transfer of LncRNAs & $(184)$ & 2D and spheroids \\
\hline $\begin{array}{l}\beta \text {-catenin nuclear translocation represses thyroid cancer stem cells differentiating into cells with sodium-iodine symporter } \\
\text { functional expression }\end{array}$ & $(185)$ & 2D and PDX \\
\hline Effect of low-dose tungsten on human thyroid stem/precursor cells and their progeny & $(186)$ & 2D and spheroid \\
\hline
\end{tabular}


biology of thyroid cancer, as well as for testing drugs prior to human trials. In the future, the promising field of personalized cancer medicine will establish effective treatment strategies based on an individual tumor's genetic profile and predicted drug response through in vitro culture techniques.

\section{AUTHOR CONTRIBUTIONS}

DC was the primary author of this article. VG and JG also reviewed articles that were included in the literature review. AR,

\section{REFERENCES}

1. Sipos JA, Mazzaferri EL. Thyroid cancer epidemiology and prognostic variables. Clin Oncol. (2010) 22:395-404. doi: 10.1016/j.clon.2010.05.004

2. Davies L, Welch HG. Increasing incidence of thyroid cancer in the united states, 1973-2002. JAMA. (2006) 295:21647. doi: 10.1001/jama.295.18.2164

3. La Vecchia C, Malvezzi M, Bosetti C, Garavello W, Bertuccio P, Levi F, et al. Thyroid cancer mortality and incidence: a global overview. Int $J$ Cancer. (2015) 136:2187-95. doi: 10.1002/ijc.29251

4. Sampson E, Brierley JD, Le LW, Rotstein L, Tsang RW. Clinical management and outcome of papillary and follicular (differentiated) thyroid cancer presenting with distant metastasis at diagnosis. Cancer. (2007) 110:14516. doi: $10.1002 / \mathrm{cncr} .22956$

5. Riley A, Green V, Cheah R, McKenzie G, Karsai L, England J, et al. A novel microfluidic device capable of maintaining functional thyroid carcinoma specimens ex vivo provides a new drug screening platform. BMC Cancer. (2019) 19:259. doi: 10.1186/s12885-019-5465-z

6. Pulvertaft RJ, Davies JR, Weiss L, Wilkinson JH. Studies on tissue cultures of human pathological thyroids. J Pathol Bacteriol. (1959) 77:1932. doi: $10.1002 /$ path. 1700770103

7. Toda S, Aoki S, Uchihashi K, Matsunobu A, Yamamoto M, Ootani A, et al. Culture models for studying thyroid biology and disorders. ISRN Endocrinol. (2011) 2011:275782. doi: 10.5402/2011/275782

8. Elsdale T, Bard J. Collagen substrata for studies on cell behavior. J Cell Biol. (1972) 54:626-637. doi: $10.1083 /$ jcb.54.3.626

9. Kimura T, Van Keymeulen A, Golstein J, Fusco A, Dumont JE, Roger PP. Regulation of thyroid cell proliferation by tSH and other factors: a critical evaluation of in vitro models. Endocr Rev. (2001) 22:63156. doi: 10.1210/edrv.22.5.0444

10. Hynds RE, Giangreco A. Concise review: the relevance of human stem cellderived organoid models for epithelial translational medicine. Stem Cells. (2013) 31:417-22. doi: 10.1002/stem.1290

11. Fang Y, Eglen RM. Three-Dimensional cell cultures in drug discovery and development. SLAS Discov. (2017) 22:45672. doi: $10.1177 / 1087057117696795$

12. Sutherland RM, Inch WR, McCredie JA, Kruuv J. A multicomponent radiation survival curve using an in vitro tumour model. Int J Radiat Biol Relat Stud Phys Chem Med. (1970) 18:491-5. doi: 10.1080/09553007014551401

13. Zanoni M, Piccinini F, Arienti C, Zamagni A, Santi S, Polico R, et al. 3D tumor spheroid models for in vitro therapeutic screening: a systematic approach to enhance the biological relevance of data obtained. Sci Rep. (2016) 6:19103. doi: 10.1038/srep19103

14. Cho SW, Kim YA, Sun HJ, Kim YA, Oh BC, Yi KH, et al. CXCL16 signaling mediated macrophage effects on tumor invasion of papillary thyroid carcinoma. Endocr Relat Cancer. (2016) 23:113-24. doi: 10.1530/ERC-15-0196

15. Galdiero MR, Varricchi G, Loffredo S, Bellevicine C, Lansione T, Ferrara AL, et al. Potential involvement of neutrophils in human thyroid cancer. PLoS ONE. (2018) 13:e0199740. doi: 10.1371/journal.pone.0199740
RE, VG, and JG contributed to proof reading and editing of the final version. All authors contributed to the article and approved the submitted version.

\section{ACKNOWLEDGMENTS}

The authors would like to acknowledge the reproduction of Figure 7 from the Open Access article by $\mathrm{Xu}$ et al. (22). Institutions: Hull University Teaching Hospitals NHS Trust, Faculty of Health Sciences-University of Hull.

16. Hoarau-Véchot J, Rafii A, Touboul C, Pasquier J. Halfway between $2 \mathrm{D}$ and animal models: are $3 \mathrm{D}$ cultures the ideal tool to study cancer-Microenvironment interactions? Int J Mol Sci. (2018) 19:1. doi: 10.3390/ijms19010181

17. Aboulkheyr Es H, Montazeri L, Aref AR, Vosough M, Baharvand H. Personalized cancer medicine: an organoid approach. Trends Biotechnol. (2018) 36:358-371. doi: 10.1016/j.tibtech.2017.12.005

18. Clevers H. Modeling development and disease with organoids. Cell. (2016) 165:1586-97. doi: 10.1016/j.cell.2016.05.082

19. Lancaster MA, Knoblich JA. Organogenesis in a dish: modeling development and disease using organoid technologies. Science. (2014) 345:1247125. doi: $10.1126 /$ science. 1247125

20. Dutta D, Heo I, Clevers H. Disease modeling in stem cellDerived 3D organoid systems. Trends Mol Med. (2017) 23:393-410. doi: 10.1016/j.molmed.2017.02.007

21. Bartfeld S, Clevers H. Stem cell-derived organoids and their application for medical research and patient treatment. J Mol Med (Berl). (2017) 95:72938. doi: 10.1007/s00109-017-1531-7

22. Xu H, Lyu X, Yi M, Zhao W, Song Y, Wu K. Organoid technology and applications in cancer research. J Hematol Oncol. (2018) 11:116. doi: 10.1186/s13045-018-0662-9

23. Kimlin LC, Casagrande G, Virador VM. In vitro three-dimensional (3D) models in cancer research: an update. Mol Carcinog. (2013) 52:16782. doi: $10.1002 / \mathrm{mc} .21844$

24. Sachs N, Clevers H. Organoid cultures for the analysis of cancer phenotypes. Curr Opin Genet Dev. (2014) 24:68-73. doi: 10.1016/j.gde.2013.11.012

25. Saito $Y$, Onishi N, Takami H, Seishima R, Inoue H, Hirata $Y$, et al. Development of a functional thyroid model based on an organoid culture system. Biochem Biophys Res Commun. (2018) 497:783-9. doi: 10.1016/j.bbrc.2018.02.154

26. Kretzschmar K, Clevers H. Organoids: modeling development and the stem cell niche in a dish. Dev Cell. (2016) 38:590600. doi: 10.1016/j.devcel.2016.08.014

27. Sachs N, de Ligt J, Kopper O, Gogola E, Bounova G, Weeber F, et al. A living biobank of breast cancer organoids captures disease heterogeneity. Cell. (2018) 172:373-86.e310. doi: 10.1016/j.cell.2017.11.010

28. Fujii M, Shimokawa M, Date S, Takano A, Matano M, Nanki K, et al. A colorectal tumor organoid library demonstrates progressive loss of niche factor requirements during tumorigenesis. Cell Stem Cell. (2016) 18:82738. doi: 10.1016/j.stem.2016.04.003

29. Gao D, Vela I, Sboner A, Iaquinta PJ, Karthaus WR, Gopalan A, et al. Organoid cultures derived from patients with advanced prostate cancer. Cell. (2014) 159:176-87. doi: 10.1016/j.cell.2014.08.016

30. Tanweer F, Green VL, Stafford ND, Greenman J. Application of microfluidic systems in management of head and neck squamous cell carcinoma. Head Neck. (2013) 35:756-63. doi: 10.1002/hed.22906

31. Hattersley SM, Sylvester DC, Dyer CE, Stafford ND, Haswell SJ, Greenman J. A microfluidic system for testing the responses of head and neck squamous cell carcinoma tissue biopsies to treatment with chemotherapy drugs. Ann Biomed Eng. (2012) 40:1277-88. doi: 10.1007/s10439-0110428-9 
32. Hou HW, Li QS, Lee GY, Kumar AP, Ong CN, Lim CT. Deformability study of breast cancer cells using microfluidics. Biomed Microdevices. (2009) 11:557-64. doi: 10.1007/s10544-008-9262-8

33. Zhang L, Wang J, Zhao L, Meng Q, Wang Q. Analysis of chemoresistance in lung cancer with a simple microfluidic device. Electrophoresis. (2010) 31:3763-70. doi: 10.1002/elps.201000265

34. Nikiforov YE. Thyroid carcinoma: molecular pathways and therapeutic targets. Mod Pathol. (2008) 21 Suppl 2:S3743. doi: $10.1038 /$ modpathol.2008.10

35. Jin S, Borkhuu O, Bao W, Yang YT. Signaling pathways in thyroid cancer and their therapeutic implications. J Clin Med Res. (2016) 8:28496. doi: 10.14740/jocmr2480w

36. Li M, Chai HF, Peng F, Meng YT, Zhang Li-Zhi, Zhang L, et al. Estrogen receptor $\beta$ upregulated by lncRNA-H19 to promote cancer stemlike properties in papillary thyroid carcinoma. Cell Death Dis. (2018) 9:1120. doi: 10.1038/s41419-018-1077-9

37. Wang S, Wu J, Ren J, Vlantis AC, Li MY, Liu SYW, et al. MicroRNA-125b interacts with foxp3 to induce autophagy in thyroid cancer. Mol Ther. (2018) 26:2295-2303. doi: 10.1016/j.ymthe.2018.06.015

38. Li D, Cui C, Chen J, Hu Z, Wang Y, Hu D. Long non-coding rNA uCA1 promotes papillary thyroid cancer cell proliferation via miR-204-mediated bRD4 activation. Mol Med Rep. (2018) 18:305967. doi: 10.3892/mmr.2018.9246

39. Gong Y, Wu W, Zou X, Liu F, Wei T, Zhu J. miR-26a inhibits thyroid cancer cell proliferation by targeting aRPP19. Am J Cancer Res. (2018) 8:1030-9.

40. Min X, Liu K, Zhu H, Zhang J. Long noncoding rNA IINC003121 inhibits proliferation and invasion of thyroid cancer cells by suppression of the phosphatidylinositol-3-Kinase (PI3K)/Akt signaling pathway. Med Sci Monit. (2018) 24:4592-601. doi: 10.12659/MSM.908652

41. Muhanhali D, Zhai T, Jiang J, Ai Z, Zhu W, Ling Y. Long non-coding antisense rNA tNRC6C-AS1 is activated in papillary thyroid cancer and promotes cancer progression by suppressing tNRC6C expression. Front Endocrinol. (2018) 9:360. doi: 10.3389/fendo.2018.00360

42. Liu F, Lou K, Zhao X, Zhang J, Chen W, Qian Y, et al. miR-214 regulates papillary thyroid carcinoma cell proliferation and metastasis by targeting pSMD10. Int J Mol Med. (2018) 42:3027-036. doi: 10.3892/ijmm.2018.3902

43. Wu X, Yan Y, Li H, Ji N, Yu T, Huang Y, et al. DNA copy number gain-mediated lncRNA IINC01061 upregulation predicts poor prognosis and promotes papillary thyroid cancer progression. Biochem Biophys Res Commun. (2018) 503:1247-53. doi: 10.1016/j.bbrc.2018.07.032

44. Jin X, Wang Z, Pang W, Zhou J, Liang Y, Yang J, et al. Upregulated hsa_circ_0004458 contributes to progression of papillary thyroid carcinoma by inhibition of miR-885-5p and activation of rAC1. Med Sci Monit. (2018) 24:5488-500. doi: 10.12659/MSM.911095

45. Wang BC, Lin GH, Wang B, Yan M, Zhang B, Yang AK, et al. UHRF1 suppression promotes cell differentiation and reduces inflammatory reaction in anaplastic thyroid cancer. Oncotarget. (2018) 9:3194557. doi: 10.18632/oncotarget.10674

46. Wang Y, Hou Z, Li D. Long noncoding rNA uCAl promotes anaplastic thyroid cancer cell proliferation via miR-135a-mediated c-myc activation. Mol Med Rep. (2018) 18:3068-76. doi: 10.3892/mmr.2018.9276

47. Wu L, Pei F, Men X, Wang K, Ma D. miR-329 inhibits papillary thyroid cancer progression via direct targeting wNT1. Oncol Lett. (2018) 16:35618. doi: 10.3892/ol.2018.9102

48. Gao X, Chen Z, Li A, Zhang X, Cai X. miR-129 regulates growth and invasion by targeting mAL2 in papillary thyroid carcinoma. Biomed Pharmacother. (2018) 105:1072-8. doi: 10.1016/j.biopha.2018.06.050

49. Han M, Chen L, Wang Y. overexpression suppresses tumorigenesis of papillary thyroid cancer via inactivation of pTEN/PI3K/AKT pathway by targeting runx2. Onco Targets Ther. (2018) 11:630516. doi: 10.2147/OTT.S172152

50. Lu HW, Liu XD. UCA1 promotes papillary thyroid carcinoma development by stimulating cell proliferation via wnt pathway. Eur Rev Med Pharmacol Sci. (2018) 22:5576-82. doi: 10.26355/eurrev_201809_15821

51. Chen LL, Gao GX, Shen FX, Chen X, Gong XH, Wu WJ. SDC4 gene silencing favors human papillary thyroid carcinoma cell apoptosis and inhibits epithelial mesenchymal transition. Mol Cells. (2018) 41:853-67. doi: 10.14348/molcells.2018.0103
52. Li Y, Li X, Pu J, Yang Q, Guan H, Ji M, et al. c-Myc is a major determinant for antitumor activity of aurora a Kinase inhibitor mLN8237 in thyroid cancer. Thyroid. (2018) 28:1642-54. doi: 10.1089/thy.2018.0183

53. Ahn SH, Henderson YC, Williams MD, Lai SY, Clayman GL. Detection of thyroid cancer stem cells in papillary thyroid carcinoma. J Clin Endocrinol Metab. (2014) 99:536-44. doi: 10.1210/jc. 2013-2558

54. Zhou Y, Xiang J, Bhandari A, Guan Y, Xia E, Zhou X, et al. CLDN10 is associated with papillary thyroid cancer progression. J Cancer. (2018) 9:4712-7. doi: 10.7150/jca.28636

55. Liu H, Deng $H$, Zhao Y, Li C, Liang Y. LncRNA xIST/miR-34a axis modulates the cell proliferation and tumor growth of thyroid cancer through mET-PI3K-AKT signaling. J Exp Clin Cancer Res. (2018) 37:279. doi: 10.1186/s13046-018-0950-9

56. Li H, Guan H, Guo Y, Liang W, Liu L, He X, et al. CITED1 promotes proliferation of papillary thyroid cancer cells via the regulation of p21 and p27. Cell Biosci. (2018) 8:57. doi: 10.1186/s13578-018-0256-9

57. Xia F, Chen Y, Jiang B, Du X, Peng Y, Wang W, et al. Long noncoding rNA hOXA-AS2 promotes papillary thyroid cancer progression by regulating miR-520c-3p/S100A4 pathway. Cell Physiol Biochem. (2018) 50:165972. doi: $10.1159 / 000494786$

58. Ma Y, Wang Q, Liu F, Ma X, Wu L, Guo F, et al. KLF5 promotes the tumorigenesis and metastatic potential of thyroid cancer cells through the nF- $\mathrm{B}$ signaling pathway. Oncol Rep. (2018) 40:260818. doi: 10.3892/or.2018.6687

59. Zheng Z, Zhou X, Cai Y, Chen E, Zhang X, Wang O, et al. TEKT4 promotes papillary thyroid cancer cell proliferation, colony formation, and metastasis through activating pI3K/Akt pathway. Endocr Pathol. (2018) 29:310-6. doi: 10.1007/s12022-018-9549-0

60. Liu Y, Li L, Liu Z, Yuan Q, Lu X. Downregulation of miR-431 expression associated with lymph node metastasis and promotes cell invasion in papillary thyroid carcinoma. Cancer Biomark. (2018) 22:72732. doi: 10.3233/CBM-181253

61. Wu WJ, Yin H, Hu JJ, Wei XZ. Long noncoding rNA IINC00313 modulates papillary thyroid cancer tumorigenesis via sponging miR-4429. Neoplasma. (2018) 65:933-42. doi: 10.4149/neo_2018_180219N125

62. Wang Y, Lin X, Fu X, Yan W, Lin F, Kuang P, et al. Long non-coding RNA BANCR regulates cancer stem cell markers in papillary thyroid cancer via the RAF/MEK/ERK signaling pathway. Oncol Rep. (2018). 40:85966. doi: 10.3892/or.2018.6502

63. Zhou X, Xia E, Bhandari A, Zheng C, Xiang J, Guan Y, et al. LRP4 promotes proliferation, migration, and invasion in papillary thyroid cancer. Biochem Biophys Res Commun. (2018) 503:257-63. doi: 10.1016/j.bbrc.201 8.06.012

64. Huang Y, Yu S, Cao S, Yin Y, Hong S, Guan H, et al. MicroRNA-222 promotes invasion and metastasis of papillary thyroid cancer through targeting protein phosphatase 2 regulatory subunit b Alpha expression. Thyroid. (2018) 28:1162-73. doi: 10.1089/thy.2017.0665

65. Wei H, Pan L, Tao D, Li R. Circular rNA circZFR contributes to papillary thyroid cancer cell proliferation and invasion by sponging miR-1261 and facilitating c8orf4 expression. Biochem Biophys Res Commun. (2018) 503:5661. doi: 10.1016/j.bbrc.2018.05.174

66. Feng K, Liu Y, Xu LJ, Zhao LF, Jia CW, Xu MY. Long noncoding rNA pVT1 enhances the viability and invasion of papillary thyroid carcinoma cells by functioning as ceRNA of microRNA-30a through mediating expression of insulin like growth factor 1 receptor. Biomed Pharmacother. (2018) 104:68698. doi: 10.1016/j.biopha.2018.05.078

67. Gu Y, Yang N, Yin L, Feng C, Liu T. Inhibitory roles of miR-9 on papillary thyroid cancer through targeting bRAF. Mol Med Rep. (2018) 18:96572. doi: $10.3892 / \mathrm{mmr} .2018 .9010$

68. Gao B, Guo L, Luo D, Jiang Y, Zhao J, Mao C, et al. Steroid receptor coactivator-1 interacts with $\mathrm{nF}-\kappa \mathrm{B}$ to increase vEGFC levels in human thyroid cancer. Biosci Rep. (2018) 38:3. doi: 10.1042/BSR201 80394

69. Li R, Dong B, Wang Z, Jiang T, Chen G. MicroRNA-361-5p inhibits papillary thyroid carcinoma progression by targeting rOCK1. Biomed Pharmacother. (2018) 102:988-95. doi: 10.1016/j.biopha.2018. 03.122 
70. Guan H, Guo Y, Liu L, Ye R, Liang W, Li H, et al. INAVA promotes aggressiveness of papillary thyroid cancer by upregulating MMP9 expression. Cell Biosci. (2018) 8:26. doi: 10.1186/s13578-018-0224-4

71. Ding S, Qu W, Jiao Y, Zhang J, Zhang C, Dang S. LncRNA sNHG12 promotes the proliferation and metastasis of papillary thyroid carcinoma cells through regulating wnt/ $\beta$-catenin signaling pathway. Cancer Biomark. (2018) 22:217-26. doi: 10.3233/CBM-170777

72. Sui X, Sui Y, Wang Y. LARP7 in papillary thyroid carcinoma induces nIS expression through suppression of the sHH signaling pathway. Mol Med Rep. (2018) 17:7521-8. doi: 10.3892/mmr.2018.8856

73. Wang R, Ma Q, Ji L, Yao Y, Ma M, Wen Q. miR-622 suppresses tumor formation by directly targeting vEGFA in papillary thyroid carcinoma. Onco Targets Ther. (2018) 11:1501-9. doi: 10.2147/OTT.S156810

74. Wächter S, Damanakis AI, Elxnat M, Roth S, Wunderlich A, Verburg FA, et al. Epigenetic modifications in thyroid cancer cells restore nIS and radio-Iodine uptake and promote cell death. J Clin Med. (2018) 7:4. doi: 10.3390/jcm7040061

75. Sun W, Lan X, Zhang H, Wang Z, Dong W, He L, et al. NEAT1_2 functions as a competing endogenous rNA to regulate aTAD2 expression by sponging microRNA-106b-5p in papillary thyroid cancer. Cell Death Dis. (2018) 9:380. doi: 10.1038/s41419-018-0418-Z

76. Liao T, Wang YJ, Hu JQ, Wang Y, Han LT, Ma B, et al. Histone methyltransferase kMT5A gene modulates oncogenesis and lipid metabolism of papillary thyroid cancer in vitro. Oncol Rep. (2018) 39:21852192. doi: $10.3892 / o r .2018 .6295$

77. Li X, Ruan X, Zhang P, Yu Y, Gao M, Yuan S, et al. TBX3 promotes proliferation of papillary thyroid carcinoma cells through facilitating pRC2-mediated p57. Oncogene. (2018) 37:2773-92. doi: 10.1038/s41388-017-0090-2

78. Liu J, Feng L, Zhang H, Zhang J, Zhang Y, Li S, et al. Effects of miR-144 on the sensitivity of human anaplastic thyroid carcinoma cells to cisplatin by autophagy regulation. Cancer Biol Ther. (2018) 19:48496. doi: 10.1080/15384047.2018.1433502

79. Beadnell TC, Nassar KW, Rose MM, Clark EG, Danysh BP, Hofmann MC, et al. Src-mediated regulation of the $\mathrm{pI} 3 \mathrm{~K}$ pathway in advanced papillary and anaplastic thyroid cancer. Oncogenesis. (2018) 7:23. doi: 10.1038/s41389-017-0015-5

80. Ye Y, Song Y, Zhuang J, He S, Ni J, Xia W. Long non-coding rNA cCAL promotes papillary thyroid cancer progression by activation of nOTCH1 pathway. Oncol Res. (2018) doi: 10.3727/096504018X15188340975709

81. Ayroldi E, Petrillo MG, Marchetti MC, Cannarile L, Ronchetti S, Ricci E, et al. Long glucocorticoid-induced leucine zipper regulates human thyroid cancer cell proliferation. Cell Death Dis. (2018) 9:305. doi: 10.1038/s41419-018-0346-y

82. Parascandolo A, Laukkanen MO, De Rosa N, Ugolini C, Cantisani MC, Cirafici AM, et al. A dual mechanism of activation of the sonic hedgehog pathway in anaplastic thyroid cancer: crosstalk with rAS-BRAF-MEK pathway and ligand secretion by tumor stroma. Oncotarget. (2018) 9:44964510. doi: 10.18632/oncotarget. 23388

83. Wen D, Liao T, Ma B, Qu N, Shi RL, Lu ZW, et al. Downregulation of cSN6 attenuates papillary thyroid carcinoma progression by reducing wnt/ $\beta$ catenin signaling and sensitizes cancer cells to fH535 therapy. Cancer Med. (2018) 7:285-96. doi: 10.1002/cam4.1272

84. Zhang H, Cai Y, Zheng L, Zhang Z, Lin X, Jiang N. Long noncoding rNA nEAT1 regulate papillary thyroid cancer progression by modulating miR-129-5p/KLK7 expression. J Cell Physiol. (2018) 233:6638-48. doi: 10.1002/jcp.26425

85. Bhandari A, Guan Y, Xia E, Huang Q, Chen Y. VASN promotes yAP/TAZ and eMT pathway in thyroid carcinogenesis in vitro. Am J Transl Res. (2019) 11:3589-99.

86. Zhang W, Sun W, Qin Y, Wu CH, He L, Zhang T, et al. Knockdown of kDM1A suppresses tumour migration and invasion by epigenetically regulating the tIMP1/MMP9 pathway in papillary thyroid cancer. J Cell Mol Med. (2019) 23:4933-44. doi: 10.1111/jcmm.14311

87. Wang YH, Huo BL, Li C, Ma G, Cao W. Knockdown of long noncoding rNA sNHG7 inhibits the proliferation and promotes apoptosis of thyroid cancer cells by downregulating bDNF. Eur Rev Med Pharmacol Sci. (2019) 23:481521. doi: 10.26355/eurrev_201906_18067
88. Zhang L, Lian R, Zhao J, Feng X, Ye R, Pan L, et al. IGFBP7 inhibits cell proliferation by suppressing aKT activity and cell cycle progression in thyroid carcinoma. Cell Biosci. (2019) 9:44. doi: 10.1186/s13578-019-0310-2

89. Collina F, La Sala L, Liotti F, Prevete N, La Mantia E, Chiofalo $\mathrm{MG}$, et al. AXL is a novel predictive factor and therapeutic target for radioactive iodine refractory thyroid cancer. Cancers (Basel). (2019) 11:6. doi: 10.3390/cancers11060785

90. Antognelli C, Moretti S, Frosini R, Puxeddu E, Sidoni A, Talesa VN. Methylglyoxal acts as a tumor-Promoting factor in anaplastic thyroid cancer. Cells. (2019) 8:6. doi: 10.3390/cells8060547

91. Zhang J, Hu L, Wang H, Zhi J, Hou X, Wu Y, et al. Functional analysis and clinical significance of the isocitrate dehydrogenase 2 gene in papillary thyroid carcinoma. Cancer Manag Res. (2019) 11:376577. doi: 10.2147/CMAR.S194920

92. Hao RT, Zheng C, Wu CY, Xia EJ, Zhou XF, Quan RD, et al. NECTIN4 promotes papillary thyroid cancer cell proliferation, migration, and invasion and triggers eMT by activating aKT. Cancer Manag Res. (2019) 11:256578. doi: 10.2147/CMAR.S190332

93. Fu X, Zhang $H$, Chen $Z$, Yang Z, Shi D, Liu $T$, et al. TFAP2B overexpression contributes to tumor growth and progression of thyroid cancer through the cOX-2 signaling pathway. Cell Death Dis. (2019) 10:397. doi: 10.1038/s41419-019-1600-7

94. Zeng J, Ma X, Wang J, Liu R, Shao Y, Hou Y, et al. Down-regulated hSDL2 expression supresses cell proliferation and promotes apoptosis in papillary thyroid carcinoma. Biosci Rep. (2019) 39:6. doi: 10.1042/BSR20190425

95. Starenki D, Sosonkina N, Hong SK, Lloyd RV, Park JI. Mortalin (GRP75/HSPA9) promotes survival and proliferation of thyroid carcinoma cells. Int J Mol Sci. (2019) 20:69. doi: 10.3390/ijms20092069

96. Liu X, Fu Q, Li S, Liang N, Li F, Li C, et al. LncRNA fOXD2-AS1 functions as a competing endogenous rNA to regulate tERT expression by sponging miR-7-5p in thyroid cancer. Front Endocrinol. (2019) 10:207. doi: 10.3389/fendo.2019.00207

97. Song YS, Yoo SK, Kim HH, Jung G, Oh AR, Cha JY, et al. Interaction of bRAF-induced eTS factors with mutant tERT promoter in papillary thyroid cancer. Endocr Relat Cancer. (2019) 26:629-41. doi: 10.1530/ERC-17-0562

98. Lathika LM, Nair JKKM, Saritha VN, Sujathan K, Sreeja S. Role of phospho-ezrin in differentiating thyroid carcinoma. Sci Rep. (2019) 9:6190. doi: 10.1038/s41598-019-42612-0

99. Chen Y, Quan R, Bhandari A, Chen Z, Guan Y, Xiang J, et al. Low metallothionein $1 \mathrm{M}(\mathrm{MT} 1 \mathrm{M})$ is associated with thyroid cancer cell lines progression. Am J Transl Res. (2019) 11:1760-70.

100. Chen J, Xu Z, Yu C, Wu Z, Yin Z, Fang F, et al. miR-758-3p regulates papillary thyroid cancer cell proliferation and migration by targeting tAB1. Pharmazie. (2019) 74:235-8. doi: 10.1691/ph.2019.8933

101. Joo LJS, Weiss J, Gill AJ, Clifton-Bligh R, Brahmbhatt H, MacDiarmid JA, et al. RET kinase-Regulated microRNA-153-3p improves therapeutic efficacy in medullary thyroid carcinoma. Thyroid. (2019) 29:830-44. doi: 10.1089/thy.2018.0525

102. Murugan AK, Liu R, Xing M. Identification and characterization of two novel oncogenic mTOR mutations. Oncogene. (2019) 38:521126. doi: 10.1038/s41388-019-0787-5

103. Fuziwara CS, Saito KC, Leoni SG, Waitzberg Â, Kimura ET. The highly expressed fAM83F protein in papillary thyroid cancer exerts a pro-Oncogenic role in thyroid follicular cells. Front Endocrinol. (2019) 10:134. doi: 10.3389/fendo.2019.00134

104. Zhao J, Yun X, Ruan X, Chi J, Yu Y, Li Y, et al. High expression of nUCB2 promotes papillary thyroid cancer cells proliferation and invasion. Onco Targets Ther. (2019) 12:1309-18. doi: 10.2147/OTT.S184560

105. Han J, Zhang M, Nie C, Jia J, Wang F, Yu J, et al. miR-215 suppresses papillary thyroid cancer proliferation, migration, and invasion through the aKT/GSK-3 $\beta /$ Snail signaling by targeting aRFGEF1. Cell Death Dis. (2019) 10:195. doi: 10.1038/s41419-019-1444-1

106. Liu W, Zhao J, Jin M, Zhou M. circRAPGEF5 contributes to papillary thyroid proliferation and metastatis by regulation miR-198/FGFR1. Mol Ther Nucleic Acids. (2019) 14:609-616. doi: 10.1016/j.omtn.2019.01.003

107. Saini S, Sripada L, Tulla K, Kumar P, Yue F, Kunda N, et al. Loss of mADD expression inhibits cellular growth and metastasis in anaplastic thyroid cancer. Cell Death Dis. (2019) 10:145. doi: 10.1038/s41419-019-1351-5 
108. Vitiello M, Palma G, Monaco M, Bello AM, Camorani S, Francesca $\mathrm{P}$, et al. Dual oncogenic/Anti-Oncogenic role of pATZ1 in fRTL5 rat thyroid cells transformed by the ha-RasV12 oncogene. Genes. (2019) 10:127. doi: 10.3390/genes10020127

109. Wen J, Wang H, Dong T, Gan P, Fang H, Wu S, et al. STAT3induced upregulation of IncRNA aBHD11-AS1 promotes tumour progression in papillary thyroid carcinoma by regulating miR-13013p/STAT3 axis and pI3K/AKT signalling pathway. Cell Prolif. (2019) 52:e12569. doi: 10.1111/cpr.12569

110. Liu Y, Li J, Li F, Li M, Shao Y, Wu L. SNHG15 functions as a tumor suppressor in thyroid cancer. J Cell Biochem. (2019) 120:6120-6. doi: 10.1002/jcb.27899

111. Reale C, Russo F, Credendino SC, Cuomo D, De Vita G, Mallardo M, et al. A toxicogenomic approach reveals a novel gene regulatory network active in in vitro and in vivo models of thyroid carcinogenesis. Int J Environ Res Public Health. (2019) 16:122. doi: 10.3390/ijerph16010122

112. Liu C, Feng Z, Chen T, Lv Juan, Liu P, Jia P, et al. Downregulation of nEAT1 reverses the radioactive iodine resistance of papillary thyroid carcinoma cell via miR-101-3p/FN1/PI3K-AKT signaling pathway. Cell Cycle. (2019) 18:167-203. doi: 10.1080/15384101.2018.1560203

113. Li X, Zhong W, Xu Y, Yu B, Liu H. Silencing of lncRNA IINC00514 inhibits the malignant behaviors of papillary thyroid cancer through miR204-3p/CDC23 axis. Biochem Biophys Res Commun. (2019) 508:11458. doi: 10.1016/j.bbrc.2018.12.051

114. Yi T, Zhou X, Sang K, Zhou J, Ge L. MicroRNA-1270 modulates papillary thyroid cancer cell development by regulating sCAI. Biomed Pharmacother. (2019) 109:2357-64. doi: 10.1016/j.biopha.2018.08.150

115. Wang N, Li Y, Wei J, Pu J, Liu R, Yang Q, et al. TBX1 functions as a tumor suppressor in thyroid cancer through inhibiting the activities of the pI3K/AKT and mAPK/ERK pathways. Thyroid. (2019) 29:37894. doi: 10.1089/thy.2018.0312

116. Jia M, Shi Y, Li Z, Lu X, Wang J. MicroRNA-146b-5p as an oncomiR promotes papillary thyroid carcinoma development by targeting cCDC6. Cancer Lett. (2019) 443:145-56. doi: 10.1016/j.canlet.2018.11.026

117. Wei X, Cai S, Boohaker RJ, Fried J, Li Y, Hu L, et al. KAT5 promotes invasion and metastasis through c-MYC stabilization in aTC. Endocr Relat Cancer. (2019) 26:141-51. doi: 10.1530/ERC-18-0193

118. Zhao J, Li Z, Chen Y, Zhang S, Guo L, Gao B, et al. MicroRNA-766 inhibits papillary thyroid cancer progression by directly targeting insulin receptor substrate 2 and regulating the pI3K/Akt pathway. Int J Oncol. (2019) 54:315-25. doi: 10.3892/ijo.2018.4615

119. Xu K, Feng Y. HOXD-AS1 is a predictor of clinical progression and functions as an oncogenic lncRNAs in papillary thyroid cancer. J Cell Biochem. (2019) 120:5326-32. doi: 10.1002/jcb.27809

120. Fang M, Huang W, Wu X, Gao Y, Ou J, Zhang X, et al. miR-141-3p suppresses tumor growth and metastasis in papillary thyroid cancer via targeting yin yang 1. Anat Rec. (2019) 302:258-68. doi: 10.1002/ar.23940

121. Sun Z, Guo X, Zang M, Wang P, Xue S, Chen G. Long non-coding rNA IINC00152 promotes cell growth and invasion of papillary thyroid carcinoma by regulating the miR-497/BDNF axis. J Cell Physiol. (2019) 234:133645. doi: $10.1002 /$ jcp. 26928

122. Cisneros Castillo LR, Oancea AD, Stüllein C, Régnier-Vigouroux A. Evaluation of consistency in spheroid invasion assays. Sci Rep. (2016) 6:28375. doi: $10.1038 /$ srep28375

123. Justus CR, Leffler N, Ruiz-Echevarria M, Yang LV. In vitro cell migration and invasion assays. J Vis Exp. (2014) 51046. doi: 10.3791/51046

124. Kramer N, Walzl A, Unger C, Rosner M, Krupitza G, Hengstschläger M, et al. In vitro cell migration and invasion assays. Mutat Res. (2013) 752:104. doi: 10.1016/j.mrrev.2012.08.001

125. Zimmermann M, Box C, Eccles SA. Two-dimensional vs. three-dimensional in vitro tumor migration and invasion assays. Methods Mol Biol. (2013) 986:227-52. doi: 10.1007/978-1-62703-311-4_15

126. Ekpe-Adewuyi E, Lopez-Campistrous A, Tang X, Brindley DN, McMullen TP. Platelet derived growth factor receptor alpha mediates nodal metastases in papillary thyroid cancer by driving the epithelial-mesenchymal transition. Oncotarget. (2016) 7:83684-700. doi: 10.18632/oncotarget. 13299

127. Hutchinson L, Kirk R. High drug attrition rates-where are we going wrong? Nat Rev Clin Oncol. (2011) 8:189-90. doi: 10.1038/nrclinonc.2011.34
128. Tahara M. Management of recurrent or metastatic thyroid cancer. ESMO Open. (2018) 3(Suppl. 1):e000359. doi: 10.1136/esmoopen-2018-000359

129. Subbiah V, Gainor JF, Rahal R, Brubaker JD, Kim JL, Maynard M, et al. Precision targeted therapy with bLU-667 for rET-Driven cancers. Cancer Discov. (2018) 8:836-849. doi: 10.1158/2159-8290.CD-18-0338

130. Li X, Li Z, Song Y, Liu W, Liu Z. The mTOR kinase inhibitor cZ415 inhibits human papillary thyroid carcinoma cell growth. Cell Physiol Biochem. (2018) 46:579-90. doi: 10.1159/000488625

131. Petruzzella E, Sirota R, Solazzo I, Gandin V, Gibson D. Triple action pt(iv) derivatives of cisplatin: a new class of potent anticancer agents that overcome resistance. Chem Sci. (2018) 9:4299-307. doi: 10.1039/C8SC00428E

132. Sauter AW, Mansi R, Hassiepen U, Muller L, Panigada T, Wiehr $\mathrm{S}$, et al. Targeting of the cholecystokinin-2 receptor with the minigastrin analog177 lu-DOTA-PP-F11N: does the use of protease inhibitors further improve in vivi distribution? J Nucl Med. (2019) 60:393-9. doi: 10.2967/jnumed.118.207845

133. Jiang K, Song C, Kong L, Hu L, Lin G, Ye T, et al. Recombinant oncolytic newcastle disease virus displays antitumor activities in anaplastic thyroid cancer cells. BMC Cancer. (2018) 18:746. doi: 10.1186/s12885-018-4522-3

134. Fanian M, Bahmani M, Mozafari M, Naderi S, Zareie MA, Okhovat MA, et al. The synergistic effects of celecoxib and sodium valproate on apoptosis and invasiveness behavior of papillary thyroid cancer cell line in-vitro. Iran J Pharm Res. (2018) 17:1008-17.

135. Thakur S, Daley B, Gaskins K, Vasko VV, Boufraqech M, Patel $\mathrm{D}$, et al. Metformin targets mitochondrial glycerophosphate dehydrogenase to control rate of oxidative phosphorylation and growth of thyroid cancer in vitro and in vivo. Clin Cancer Res. (2018) 24:4030-43. doi: 10.1158/1078-0432.CCR-17-3167

136. Subbiah V, Velcheti V, Tuch BB, Ebata K, Busaidy NL, Cabanillas ME, et al. Selective rET kinase inhibition for patients with rET-altered cancers. Ann Oncol. (2018) 29:1869-76. doi: 10.1093/annonc/mdy137

137. Milošević Z, Banković J, Dinić J, Tsimplouli C, Sereti E, Dragoj M, et al. Potential of the dual mTOR kinase inhibitor aZD2014 to overcome paclitaxel resistance in anaplastic thyroid carcinoma. Cell Oncol (Dordr). (2018) 41:409-26. doi: 10.1007/s13402-018-0380-x

138. Yang PS, Hsu YC, Lee JJ, Chen MJ, Huang SY, Cheng SP. Heme oxygenase1 inhibitors induce cell cycle arrest and suppress tumor growth in thyroid cancer cells. Int J Mol Sci. (2018) 19:2502. doi: 10.3390/ijms19092502

139. Li Z, Jiang X, Chen P, Wu X, Duan A, Qin Y. Combined effects of octreotide and cisplatin on the proliferation of side population cells from anaplastic thyroid cancer cell lines. Oncol Lett. (2018) 16:4033-42. doi: 10.3892/ol.2018.9105

140. Häfliger P, Graff J, Rubin M, Stooss A, Dettmer MS, Altmann KH, et al. The lAT1 inhibitor jPH203 reduces growth of thyroid carcinoma in a fully immunocompetent mouse model. J Exp Clin Cancer Res. (2018) 37:234. doi: 10.1186/s13046-018-0907-z

141. Zhu X, Holmsen E, Park S, Willingham MC, Qi J, Cheng SY. Synergistic effects of bET and $\mathrm{mEK}$ inhibitors promote regression of anaplastic thyroid tumors. Oncotarget. (2018) 9:35408-35421. doi: 10.18632/oncotarget.26253

142. Feng H, Cheng X, Kuang J, Chen L, Yuen S, Shi M, et al. Apatinibinduced protective autophagy and apoptosis through the aKTmTOR pathway in anaplastic thyroid cancer. Cell Death Dis. (2018) 9:1030. doi: 10.1038/s41419-018-1054-3

143. Kim SY, Kim SM, Chang HJ, Kim BW, Lee YS, Park CS, et al. SoLAT (Sorafenib lenvatinib alternating treatment): a new treatment protocol with alternating sorafenib and lenvatinib for refractory thyroid cancer. $B M C$ Cancer. (2018) 18:956. doi: 10.1186/s12885-018-4854-Z

144. Jiao X, Zhang $\mathrm{H}$, Xu X, Yu Y, Zhang $H$, Zhang J, et al. S100A4 knockout sensitizes anaplastic thyroid carcinoma cells harboring bRAFV600E/Mt to vemurafenib. Cell Physiol Biochem. (2018) 49:1143-162. doi: 10.1159/000493296

145. Pinto N, Prokopec SD, Vizeacoumar F, Searle K, Lowerison M, Ruicci KM, et al. Lestaurtinib is a potent inhibitor of anaplastic thyroid cancer cell line models. PLoS ONE. (2018) 13:e0207152. doi: 10.1371/journal.pone.0207152

146. Gianì F, Russo G, Pennisi M, Sciacca L, Frasca F, Pappalardo F. Computational modeling reveals $\mathrm{mAP} 3 \mathrm{~K} 8$ as mediator of resistance to vemurafenib in thyroid cancer stem cells. Bioinformatics. (2018) 35:2267-75. doi: 10.1093/bioinformatics/bty969 
147. Shi GH, Zhou L. Emodin suppresses angiogenesis and metastasis in anaplastic thyroid cancer by affecting tRAF6-mediated pathways in vivo and in vitro. Mol Med Rep. (2018) 18:5191-7. doi: 10.3892/mmr.201 8.9510

148. De Martino D, Yilmaz E, Orlacchio A, Ranieri M, Zhao K, Di Cristofano A. PI3K blockage synergizes with pLK1 inhibition preventing endoreduplication and enhancing apoptosis in anaplastic thyroid cancer. Cancer Lett. (2018) 439:56-65. doi: 10.1016/j.canlet.2018.09.024

149. Ke Y, Xiang C. Transferrin receptor-targeted hMSN for sorafenib delivery in refractory differentiated thyroid cancer therapy. Int J Nanomedicine. (2018) 13:8339-54. doi: 10.2147/IJN.S187240

150. Lombardo GE, Maggisano V, Celano M, Cosco D, Mignogna C, Baldan F, et al. Anti-hTERT siRNA-loaded nanoparticles block the growth of anaplastic thyroid cancer xenograft. Mol Cancer Ther. (2018) 17:118795. doi: 10.1158/1535-7163.MCT-17-0559

151. Zou ZW, Liu T, Li Y, Chen P, Peng X, Ma C, et al. Melatonin suppresses thyroid cancer growth and overcomes radioresistance via inhibition of p65 phosphorylation and induction of rOS. Redox Biol. (2018) 16:22636. doi: 10.1016/j.redox.2018.02.025

152. Ferrari SM, Bocci G, Di Desidero T, Ruffilli I, Elia G, Ragusa F, et al. Vandetanib has antineoplastic activity in anaplastic thyroid cancer, in vitro and in vivo. Oncol Rep. (2018) 39:2306-14. doi: 10.3892/or.2018.6305

153. Ferrari SM, Bocci G, Di Desidero T, Elia G, Ruffilli I, Ragusa F, et al. Lenvatinib exhibits antineoplastic activity in anaplastic thyroid cancer in vitro and in vivo. Oncol Rep. (2018) 39:2225-34. doi: 10.3892/or.2018.6306

154. Wang CY, Shui HA, Chang TC. Dual effects for lovastatin in anaplastic thyroid cancer: the pivotal effect of transketolase (TKT) on lovastatin and tumor proliferation. J Investig Med. (2018) 66:1-9. doi: 10.1136/jim-2017-000634

155. Lee YR, Chen SH, Lin CY, Chao WY, Lim YP, Yu HI, et al. In vitro antitumor activity of aloperine on human thyroid cancer cells through caspasedependent apoptosis. Int J Mol Sci. (2018) 19:312. doi: 10.3390/ijms19010312

156. Yu T, Tong L, Ao Y, Zhang G, Liu Y, Zhang H. Novel design of nIR-triggered plasmonic nanodots capped mesoporous silica nanoparticles loaded with natural capsaicin to inhibition of metastasis of human papillary thyroid carcinoma b-CPAP cells in thyroid cancer chemo-photothermal therapy. J Photochem Photobiol B. (2019) 197:111534. doi: 10.1016/j.jphotobiol.2019.111534

157. Wang Y, Xie F, Chen D, Wang L. Inhibition of mitochondrial respiration by tigecycline selectively targets thyroid carcinoma and increases chemosensitivity. Clin Exp Pharmacol Physiol. (2019) 46:890-7. doi: 10.1111/1440-1681.13126

158. Lin SF, Lin JD, Yeh CN, Huang YT, Chou TC, Wong RJ. Targeting pLKs as a therapeutic approach to well-differentiated thyroid cancer. Endocr Relat Cancer. (2019) 26:727-38. doi: 10.1530/ERC-18-0555

159. Samimi H, Haghpanah V, Irani S, Arefian E, Sohi AN, Fallah P, et al. Transcript-level regulation of mALAT1-mediated cell cycle and apoptosis genes using dual mEK/Aurora kinase inhibitor "BI-847325" on anaplastic thyroid carcinoma. Daru. (2019) 27:1-7. doi: 10.1007/s40199-018-0231-3

160. Hu Y, Liang LB, Zhang Q, Lan F, Lin $\mathrm{K}, \mathrm{He} \mathrm{H}$, et al. Effect of nifuroxazide on proliferation, migration, and invasion of thyroid papillary carcinoma cells. Sichuan Da Xue Xue Bao Yi Xue Ban. (2019) 50:48-54.

161. Zhang R, Zhang Y, Tan J, Wang H, Zhang G, Li N, et al. Antitumor effect of 131I-labelled anti-VEGFR2 targeted mesoporous silica nanoparticles in anaplastic thyroid cancer. Nanoscale Res Lett. (2019) 14:96. doi: 10.1186/s11671-019-2924-Z

162. Fu H, Cheng L, Jin Y, Cheng L, Liu M, Chen L. MAPK inhibitors enhance hDAC inhibitor-Induced redifferentiation in papillary thyroid cancer cells harboring bRAFV600E: an in vitro study. Mol Ther Oncolytics. (2019) 12:235-45. doi: 10.1016/j.omto.2019.01.007

163. Owonikoko TK, Zhang G, Lallani SB, Chen Z, Martinson DE, Khuri FR, et al. Evaluation of preclinical efficacy of everolimus and pasireotide in thyroid cancer cell lines and xenograft models. PLoS ONE. (2019) 14:e0206309. doi: 10.1371/journal.pone.0206309

164. Chen F, Li M, Zhu X. Propofol suppresses proliferation and migration of papillary thyroid cancer cells by down-regulation of lncRNA aNRIL. Exp Mol Pathol. (2019) 107:68-76. doi: 10.1016/j.yexmp.2019.01.011
165. Kim J, Song J, Ji HD, Yoo EK, Lee JE, Lee SB, et al. Discovery of potent, selective, and orally bioavailable estrogen-Related receptor- $\gamma$ inverse agonists to restore the sodium iodide symporter function in anaplastic thyroid cancer. J Med Chem. (2019) 62:1837-58. doi: 10.1021/acs.jmedchem.8b01296

166. Ruan X, Shi X, Dong Q, Yu Y, Hou X, Song X, et al. Antitumor effects of anlotinib in thyroid cancer. Endocr Relat Cancer. (2019) 26:15364. doi: 10.1530/ERC-17-0558

167. Zhang J, Saltzman M. Engineering biodegradable nanoparticles for drug and gene delivery. Chem Eng Prog. (2013) 109:25-30.

168. Li W, Reeb AN, Sewell WA, Elhomsy G, Lin RY. Phenotypic characterization of metastatic anaplastic thyroid cancer stem cells. PLoS ONE. (2013) 8:e65095. doi: 10.1371/journal.pone.0065095

169. Giuffrida R, Adamo L, Iannolo G, Vicari L, Giuffrida D, Eramo A, et al. Resistance of papillary thyroid cancer stem cells to chemotherapy. Oncol Lett. (2016) 12:687-91. doi: 10.3892/ol.2016.4666

170. Hardin $\mathrm{H}$, Yu XM, Harrison AD, Larrain C, Zhang $\mathrm{R}$, Chen J, et al. Generation of novel thyroid cancer stem-Like cell clones: effects of resveratrol and valproic acid. Am J Pathol. (2016) 186:1662-73. doi: 10.1016/j.ajpath.2016.02.003

171. Wicha MS, Liu S, Dontu G. Cancer stem cells: an old idea-a paradigm shift. Cancer Res. (2006) 66:1883-90; discussion $\quad 1895-86 . \quad$ doi: $10.1158 / 0008-5472 . C A N-0$ 5-3153

172. Nagayama Y, Shimamura M, Mitsutake N. Cancer stem cells in the thyroid. Front Endocrinol. (2016) 7:20. doi: 10.3389/fendo.2016.00020

173. Zito G, Richiusa P, Bommarito A, Carissimi E, Russo L, Coppola A, et al. In vitro identification and characterization of $\mathrm{cD} 133$ (pos) cancer stemlike cells in anaplastic thyroid carcinoma cell lines. PLoS ONE. (2008) 3:e3544. doi: 10.1371/journal.pone.0003544

174. Zhu W, Hai T, Ye L, Cote GJ. Medullary thyroid carcinoma cell lines contain a self-renewing cD133+ population that is dependent on ret proto-oncogene activity. J Clin Endocrinol Metab. (2010) 95:43944. doi: 10.1210/jc.2009-1485

175. Todaro M, Iovino F, Eterno V, Cammareri P, Gambara G, Espina V, et al. Tumorigenic and metastatic activity of human thyroid cancer stem cells. Cancer Res. (2010) 70:8874-85. doi: 10.1158/0008-5472.CAN-10-1994

176. Zheng X, Cui D, Xu S, Brabant G, Derwahl M. Doxorubicin fails to eradicate cancer stem cells derived from anaplastic thyroid carcinoma cells: characterization of resistant cells. Int J Oncol. (2010) 37:30715. doi: 10.3892/ijo_00000679

177. Malaguarnera R, Frasca F, Garozzo A, Gianì F, Giuseppe P, Vella V, et al. Insulin receptor isoforms and insulin-like growth factor receptor in human follicular cell precursors from papillary thyroid cancer and normal thyroid. $J$ Clin Endocrinol Metab. (2011) 96:766-74. doi: 10.1210/jc.2010-1255

178. Yasui K, Shimamura M, Mitsutake N, Nagayama Y. SNAIL induces epithelial-to-mesenchymal transition and cancer stem cell-like properties in aldehyde dehydroghenase-negative thyroid cancer cells. Thyroid. (2013) 23:989-96. doi: 10.1089/thy.2012.0319

179. Shimamura M, Nagayama Y, Matsuse M, Yamashita S, Mitsutake N. Analysis of multiple markers for cancer stem-like cells in human thyroid carcinoma cell lines. Endocr J. (2014) 61:481-90. doi: 10.1507/endocrj.EJ1 3-0526

180. Ma R, Minsky N, Morshed SA, Davies TF. Stemness in human thyroid cancers and derived cell lines: the role of asymmetrically dividing cancer stem cells resistant to chemotherapy. J Clin Endocrinol Metab. (2014) 99:E4009. doi: 10.1210/jc.2013-3545

181. Gianì F, Vella V, Nicolosi ML, Fierabracci A, Lotta S, Malaguarnera R, et al. Thyrospheres from normal or malignant thyroid tissue have different biological, functional, and genetic features. J Clin Endocrinol Metab. (2015) 100:E1168-78. doi: 10.1210/jc.2014-4163

182. Dima M, Pecce V, Biffoni M, Di Gioia CRT, Tallini G, Biffoni M, et al. Molecular profiles of cancer stem-like cell populations in aggressive thyroid cancers. Endocrine. (2016) 53:145-56. doi: 10.1007/s12020-015-0739-y

183. Shimamura M, Yamamoto K, Kurashige T, Nagayama $Y$. Intracellular redox status controls spherogenicity, an in vitro cancer stem cell marker, in thyroid cancer cell lines. Exp Cell Res. (2018) 370:699707. doi: 10.1016/j.yexcr.2018.07.036 
184. Hardin H, Helein H, Meyer K, Robertson S, Zhang R, Zhong W, et al. Thyroid cancer stem-like cell exosomes: regulation of eMT via transfer of lncRNAs. Lab Invest. (2018) 98:1133-42. doi: 10.1038/s41374-018-0065-0

185. Lan L, Deng W, Cui D, Chen HL, Huo LL, Zuo QY, et al. $\beta$-catenin nuclear translocation represses thyroid cancer stem cells differentiating into cells with sodium-iodine symporter functional expression. Zhonghua Yi Xue Za Zhi. (2019). 99:1904-10. doi: 10.3760/cma.j.issn.0376-2491.2019.24.013

186. Gianì F, Pandini G, Scalisi NM, Vigneri P, Fazzari C, Malandrino P, et al. Effect of low-dose tungsten on human thyroid stem/precursor cells and their progeny. Endocr Relat Cancer. (2019) 26:713-25. doi: 10.1530/ERC-19-0176

187. Mitsutake N, Iwao A, Nagai K, Namba H, Ohtsuru A, Saenko V, et al. Characterization of side population in thyroid cancer cell lines: cancer stemlike cells are enriched partly but not exclusively. Endocrinology. (2007) 148:1797-803. doi: 10.1210/en.2006-1553
188. Lin RY. Thyroid cancer stem cells. Nat Rev Endocrinol. (2011) 7:60916. doi: $10.1038 /$ nrendo. 2011.127

Conflict of Interest: The authors declare that the research was conducted in the absence of any commercial or financial relationships that could be construed as a potential conflict of interest.

Copyright (๑) 2020 Chew, Green, Riley, England and Greenman. This is an openaccess article distributed under the terms of the Creative Commons Attribution License (CC BY). The use, distribution or reproduction in other forums is permitted, provided the original author(s) and the copyright owner(s) are credited and that the original publication in this journal is cited, in accordance with accepted academic practice. No use, distribution or reproduction is permitted which does not comply with these terms. 